\title{
Geochemistry of Soils from the San Rafael Valley, Santa Cruz County, Arizona
}

By Helen W. Folger and Floyd Gray

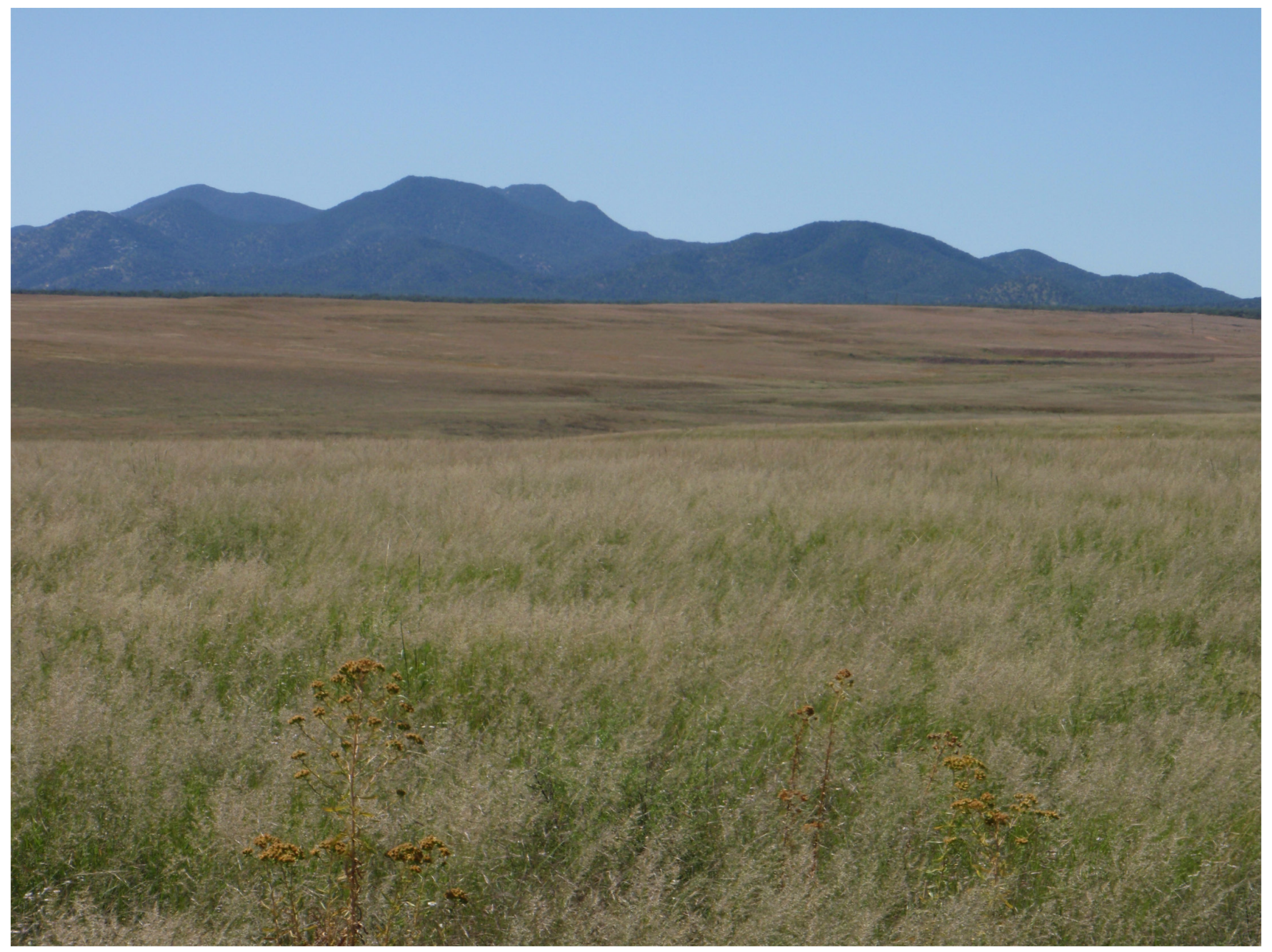

Open-File Report 2013-1149 


\title{
U.S. Department of the Interior SALLY JEWELL, Secretary
}

\section{U.S. Geological Survey Suzette M. Kimball, Acting Director}

\author{
U.S. Geological Survey, Reston, Virginia: 2013
}

For more information on the USGS - the Federal source for science about the Earth, its natural and living resources, natural hazards, and the environment, visit http://www.usgs.gov or call 1-888-ASK-USGS.

For an overview of USGS information products, including maps, imagery, and publications, visit http://www.usgs.gov/pubprod

To order this and other USGS information products, visit http://store.usgs.gov

Any use of trade, firm, or product names is for descriptive purposes only and does not imply endorsement by the U.S. Government.

Although this information product, for the most part, is in the public domain, it also may contain copyrighted materials as noted in the text. Permission to reproduce copyrighted items must be secured from the copyright owner.

Suggested citation:

Folger, H.W., and Gray, Floyd, 2013, Geochemistry of soils from the San Rafael Valley, Santa Cruz County, Arizona: U.S. Geological Survey Open-File Report 2013-1149, 30 p., 5 tables, http://dx.doi.org/10.3133/ofr20131149.

Cover: San Rafael Valley, Santa Cruz County, Arizona 


\section{Contents}

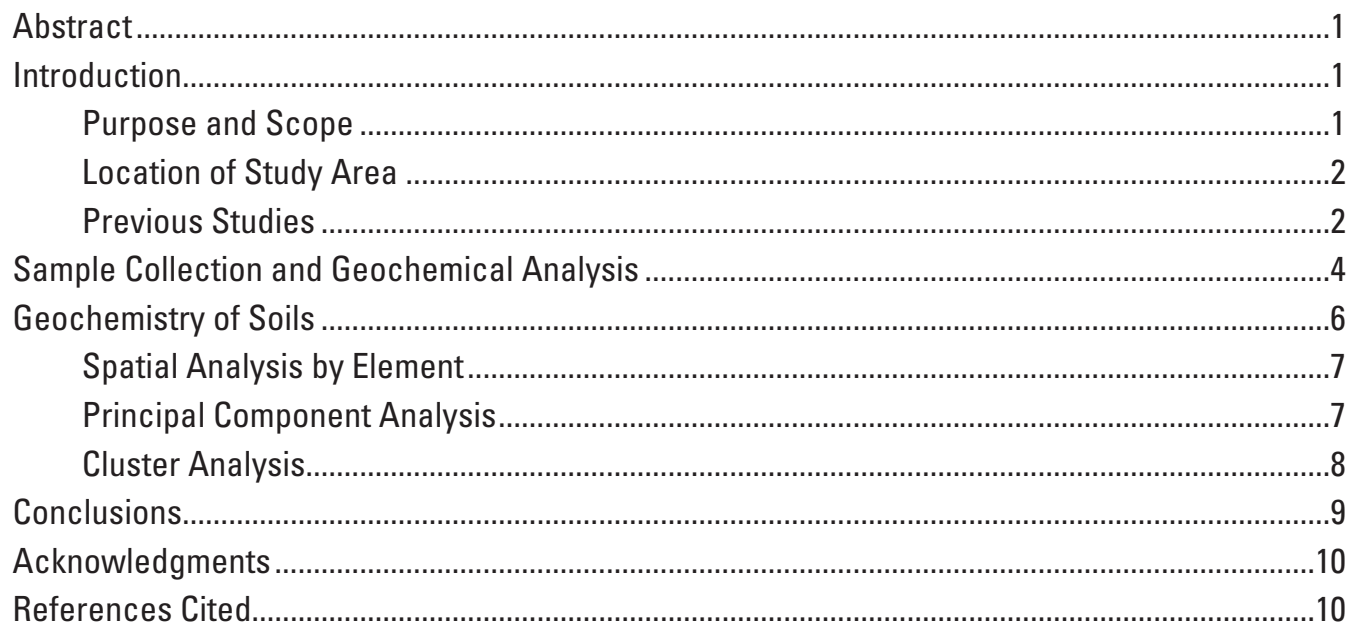

Appendixes

A. Thematic maps showing sample location and distribution of selected trace elements in soil.

B. Thematic maps showing distribution of factor scores determined from inductively coupled plasma-mass spectrometry analyses of soil samples.

C. Thematic maps showing distribution of factor scores determined from response ratios for Mobile Metal lon ${ }^{\mathrm{TM}}$ analyses of soil samples

D. Thematic maps and biplots showing cluster results from inductively coupled plasma-mass spectrometry and Mobile Metal Ion ${ }^{\mathrm{TM}}$ analyses of soil samples

\section{Figures}

1. Index map of the San Rafael Valley, Santa Cruz County, Arizona .....................................2

2. Geologic map showing soil-sampling locations, San Rafael Valley and surrounding area, Santa Cruz County, Arizona.

3. Geologic map of San Rafael Valley, Santa Cruz County, Arizona, showing mines, prospects, and their primary commodities, and the location of the inferred granite pluton and mining districts.

A1. Geologic map of San Rafael Valley, Santa Cruz County, Arizona, showing sample location and copper concentrations in parts per million in soil samples analyzed by inductively coupled plasma-mass spectrometry

A2. Geologic map of San Rafael Valley, Santa Cruz County, Arizona, showing sample location and copper concentrations in parts per million in soil samples analyzed by Mobile Metal Ion ${ }^{\mathrm{TM}}$

A3. Geologic map of San Rafael Valley, Santa Cruz County, Arizona, showing sample location and molybdenum concentrations in soil samples analyzed by inductively coupled plasma-mass spectrometry

A4. Geologic map of San Rafael Valley, Santa Cruz County, Arizona, showing sample location and molybdenum concentrations in soil samples analyzed by Mobile Metal Ion ${ }^{\mathrm{TM}}$ 
A5. Geologic map of San Rafael Valley, Santa Cruz County, Arizona, showing sample location and calcium concentrations in soil samples analyzed by inductively coupled plasma-mass spectrometry

A6. Geologic map of San Rafael Valley, Santa Cruz County, Arizona, showing sample location and calcium concentrations in soil samples analyzed by Mobile Metal $\operatorname{Ion}^{\mathrm{TM}}$.

A7. Geologic map of San Rafael Valley, Santa Cruz County, Arizona, showing sample location and iron concentrations in soil samples analyzed by inductively coupled plasma-mass spectrometry

A8. Geologic map of San Rafael Valley, Santa Cruz County, Arizona, showing sample location and iron concentrations in soil samples analyzed by Mobile Metal Ion ${ }^{\mathrm{TM}}$. .16

A9. Geologic map of San Rafael Valley, Santa Cruz County, Arizona, showing sample location and sulfur concentrations in soil samples analyzed by inductively coupled plasma-mass spectrometry

A10. Geologic map of San Rafael Valley, Santa Cruz County, Arizona, showing sample location and potassium concentrations in soil samples analyzed by inductively coupled plasma-mass spectrometry.

A11. Geologic map of San Rafael Valley, Santa Cruz County, Arizona, showing sample location and manganese concentrations in soil samples analyzed by inductively coupled plasma-mass spectrometry

A12. Geologic map of San Rafael Valley, Santa Cruz County, Arizona, showing sample location and zinc concentrations in soil samples analyzed by inductively coupled plasma-mass spectrometry

B1. Geologic map of San Rafael Valley, Santa Cruz County, Arizona, showing location of soil samples with factor scores displayed for factor 1 elements

B2. Geologic map of San Rafael Valley, Santa Cruz County, Arizona, showing location of soil samples with factor scores displayed for factor 2 elements

B3. Geologic map of San Rafael Valley, Santa Cruz County, Arizona, showing location of soil samples with factor scores displayed for factor 3 elements

B4. Geologic map of San Rafael Valley, Santa Cruz County, Arizona, showing location of soil samples with factor scores displayed for factor 4 elements

B5. Geologic map of San Rafael Valley, Santa Cruz County, Arizona, showing location of soil samples with factor scores displayed for factor 5 elements

B6. Geologic map of San Rafael Valley, Santa Cruz County, Arizona, showing location of soil samples with factor scores displayed for factor 6 elements

B7. Geologic map of San Rafael Valley, Santa Cruz County, Arizona, showing location of soil samples with factor scores displayed for factor 7 elements

B8. Geologic map of San Rafael Valley, Santa Cruz County, Arizona, showing location of soil samples with factor scores displayed for factor 8 elements

C1. Geologic map of San Rafael Valley, Santa Cruz County, Arizona, showing location of soil samples with factor scores displayed for factor 1 elements

C2. Geologic map of San Rafael Valley, Santa Cruz County, Arizona, showing location of soil samples with factor scores displayed for factor 2 elements

C3. Geologic map of San Rafael Valley, Santa Cruz County, Arizona, showing location of soil samples with factor scores displayed for factor 3 elements

C4. Geologic map of San Rafael Valley, Santa Cruz County, Arizona, showing location of soil samples with factor scores displayed for factor 4 elements .26

C5. Geologic map of San Rafael Valley, Santa Cruz County, Arizona, showing location of soil samples with factor scores displayed for factor 5 elements 
C6. Geologic map of San Rafael Valley, Santa Cruz County, Arizona, showing location

of soil samples with factor scores displayed for the factor 6 element...

C7. Geologic map of San Rafael Valley, Santa Cruz County, Arizona, showing location of soil samples with factor scores displayed for the factor 7 element... . .27

D1a and D1b. Cluster groupings based on inductively coupled plasma-mass spectrometry analyses of soil samples plotted in figure D1a on a geologic map of the San Rafael Valley, Santa Cruz County, Arizona, and biplot with biplot rays showing the four distinct clusters in figure D1b.

D2a and D2b. Cluster groupings based on Mobile Metal Ion ${ }^{\mathrm{TM}}$ analyses of soil samples plotted in figure D2a on a geologic map of the San Rafael Valley, Santa Cruz County, Arizona, and biplot with biplot rays showing the four distinct clusters in figure $\mathrm{D} 2 \mathrm{~b}$.

D3a and D3b. Cluster groupings of the combined inductively coupled plasma-mass spectrometry and Mobile Metal Ion ${ }^{\mathrm{TM}}$ analyses of soil samples plotted in figure D3a on a geologic map of the San Rafael Valley, Santa Cruz County, Arizona, and biplot with biplot rays showing the five distinct clusters in figure D3b.

\section{Tables}

1. Geochemical analyses of soil samples, by element and method of analysis, San Rafael Valley, Arizona... Available in a separate file

2. Lower limit of detection for the inductively coupled plasma-mass spectrometry and Mobile Metal Ion ${ }^{\mathrm{TM}}$ analytical methods Available in a separate file

3. Univariate statistics and percentiles for all soil sample analytical results, San Rafael Valley, Arizona. Available in a separate file

4. Factor scores of log-transformed results of inductively coupled plasma-mass spectrometry of soil samples with explained variance, San Rafael Valley, Arizona . Available in a separate file

5. Factor scores of log-transformed results of Mobile Metal Ion $^{\mathrm{TM}}$ analyses of soil samples with explained variance, San Rafael Valley, Arizona Available in a separate file 


\section{Conversion Factors}

SI to Inch/Pound

\begin{tabular}{|c|c|c|}
\hline Multiply & By & To obtain \\
\hline \multicolumn{3}{|c|}{ Length } \\
\hline centimeter $(\mathrm{cm})$ & 0.3937 & inch (in.) \\
\hline millimeter $(\mathrm{mm})$ & 0.03937 & inch (in.) \\
\hline meter $(\mathrm{m})$ & 3.281 & foot $(\mathrm{ft})$ \\
\hline kilometer $(\mathrm{km})$ & 0.6214 & mile (mi) \\
\hline kilometer (km) & 0.5400 & mile, nautical (nmi) \\
\hline meter $(\mathrm{m})$ & 1.094 & yard (yd) \\
\hline \multicolumn{3}{|c|}{ Area } \\
\hline square meter $\left(\mathrm{m}^{2}\right)$ & 0.0002471 & acre \\
\hline hectare (ha) & 2.471 & acre \\
\hline square hectometer $\left(\mathrm{hm}^{2}\right)$ & 2.471 & acre \\
\hline square kilometer $\left(\mathrm{km}^{2}\right)$ & 247.1 & acre \\
\hline square centimeter $\left(\mathrm{cm}^{2}\right)$ & 0.001076 & square foot $\left(\mathrm{ft}^{2}\right)$ \\
\hline square meter $\left(\mathrm{m}^{2}\right)$ & 10.76 & square foot $\left(\mathrm{ft}^{2}\right)$ \\
\hline square centimeter $\left(\mathrm{cm}^{2}\right)$ & 0.1550 & square inch $\left(\mathrm{in}^{2}\right)$ \\
\hline square hectometer $\left(\mathrm{hm}^{2}\right)$ & 0.003861 & section ( 640 acres or 1 square mile) \\
\hline hectare (ha) & 0.003861 & square mile $\left(\mathrm{mi}^{2}\right)$ \\
\hline square kilometer $\left(\mathrm{km}^{2}\right)$ & 0.3861 & square mile $\left(\mathrm{mi}^{2}\right)$ \\
\hline \multicolumn{3}{|c|}{ Mass } \\
\hline $\operatorname{gram}(\mathrm{g})$ & 0.03527 & ounce, avoirdupois (oz) \\
\hline kilogram (kg) & 2.205 & pound avoirdupois (lb) \\
\hline megagram $(\mathrm{Mg})$ & 1.102 & ton, short $(2,000 \mathrm{lb})$ \\
\hline megagram (Mg) & 0.9842 & ton, long $(2,240 \mathrm{lb})$ \\
\hline metric ton per day & 1.102 & ton per day (ton/d) \\
\hline megagram per day $(\mathrm{Mg} / \mathrm{d})$ & 1.102 & ton per day (ton/d) \\
\hline $\begin{array}{l}\text { megagram per day per square } \\
\text { kilometer }\left[(\mathrm{Mg} / \mathrm{d}) / \mathrm{km}^{2}\right]\end{array}$ & 2.8547 & $\begin{array}{l}\text { ton per day per square mile } \\
{\left[(\text { ton } / \mathrm{d}) / \mathrm{mi}^{2}\right]}\end{array}$ \\
\hline megagram per year (Mg/yr) & 1.102 & ton per year (ton/yr) \\
\hline metric ton per year & 1.102 & ton per year (ton/yr) \\
\hline
\end{tabular}

Vertical coordinate information is referenced to the North American Vertical Datum of 1988 (NAVD 88).

Horizontal coordinate information is referenced to the World Geographic System Datum of 1984 (WGS 84), except in figure 1, where it is referenced to the North American Datum of 1983 (NAD 83).

Elevation, as used in this report, refers to distance above the vertical datum.

Concentrations of chemical constituents in soil are given in either parts per million (ppm), parts per billion (ppb), or percent (pct, \%). 


\title{
Geochemistry of soils from the San Rafael Valley, Santa Cruz County, Arizona
}

\author{
By Helen W. Folger and Floyd Gray
}

\begin{abstract}
This study was conducted to determine whether surficial geochemical methods can be used to identify subsurface mineral deposits covered by alluvium derived from surrounding areas. The geochemical investigation focused on an anomalous geophysical magnetic high located in the San Rafael Valley in Santa Cruz County, Arizona. The magnetic high, inferred to be associated with a buried granite intrusion, occurs beneath Quaternary alluvial and terrace deposits. Soil samples were collected at a depth of 10 to 30 centimeters below land surface along transects that traverse the inferred granite. The samples were analyzed by inductively coupled plasma-mass spectrometry and by the partial-leach Mobile Metal Ion $^{\mathrm{TM}}$ method. Principal component and factor analyses showed a strong correlation between the soils and source rocks hosting base-metal replacement deposits in the Harshaw and Patagonia Mining Districts. Factor analysis also indicated areas of high metal concentrations associated with the Meadow Valley Flat. Although no definitive geochemical signature was identified for the inferred granite, concentrations of tungsten and iron in the surrounding area were slightly elevated.
\end{abstract}

\section{Introduction}

The study of soil chemistry in the San Rafael Valley is part of the Concealed Mineral Deposits project conducted by the U.S. Geological Survey (USGS) during the summers of 2008 and 2009. The objective was to determine whether a geochemical signal associated with a geophysical anomaly, interpreted as a buried granite pluton, can be discerned from the geochemical characteristics of overlying Quaternary sediments derived from a variety of adjacent source-rock areas. Two different methods of geochemical analysis were used. Fifty-eight soil samples were analyzed for 50 elements by inductively coupled plasma-mass spectrometry (ICP-MS; SGS, 2009a) and for 53 elements by the Mobile Metal Ion ${ }^{\mathrm{TM}}$ method (MMI, a proprietary analytical method of the Mineral Services Division of SGS (Société Générale de Surveillance) Canada Incorporated; SGS, 2009b). The results of both methods are compared by using factor analysis and are displayed in thematic maps by using ArcGIS (Esri; www.esri.com).

The inferred granite lies about 13 kilometers $(\mathrm{km})$ from the Red Mountain porphyry copper deposit to the northeast and about $10 \mathrm{~km}$ from the base-metal replacement deposits of the Harshaw, Mowry, and Washington Camp Mining Districts located in the Patagonia Mountains to the west. Of particular interest is whether the inferred granite intrusion has a distinct geochemical signature and whether geochemical indicators of economic mineralization may be associated with it.

\section{Purpose and Scope}

This report presents the results of two methods of geochemical analysis of 58 soil samples associated with an inferred buried granite intrusion. Two analytical methods, ICP-MS and MMI ${ }^{\mathrm{TM}}$, were used to determine the concentrations of 50 and 53 elements, respectively. The spatial distribution of the elements found in the soil samples is presented, and the results of principal component analysis and factor analysis of the analytical results are discussed. 


\section{Location of Study Area}

The San Rafael Valley lies at an elevation between 4,500 and 5,000 feet (1,370 and 1,520 meters (m)) and follows the Santa Cruz River from its headwaters in the adjacent Patagonia Mountains and Canelo Hills to the United States-Mexico border (figs. 1 and 2). Most of the land surrounding the valley is part of the Coronado National Forest. The valley area covers approximately 90,000 acres (364 $\mathrm{km}^{2}$ (square kilometers)) (Eatherly, 2010) and is used primarily for ranching and livestock. The private land of the San Rafael De La Zanja Land Grant is located in the central part of the valley. The valley, shown in the photograph on the cover of this report, has been identified as one of the last remaining short grass prairies in Arizona. Efforts by conservationists to preserve the prairie lands include the purchase of the San Rafael Land Grant by the Nature Conservancy in the late 1990s and the purchase of the adjacent San Antonio Ranch and the Upper 17 Ranch by the Arizona State Park system in 1998 (Eatherly, 2010).

The headwaters of the Santa Cruz River begin in the foothills of the Patagonia Mountains to the west, the Canelo Hills to the north and east, and the Saddle Mountains to the north. The river flows almost directly south into Sonora, Mexico, before turning west and north again, back into Arizona. Flow is intermittent in many of the upper reaches of the Santa Cruz River, where average annual rainfall is 18 inches (45.7 centimeters $(\mathrm{cm})$ ) (National Oceanic and Atmospheric Administration, 2011).

\section{Previous Studies}

The study area (fig. 2) is located in the porphyry copper metallogenic province in the southwestern United States, an area of extensive mineral wealth. The province, which has more than 50 identified porphyry copper deposits (Sawyer and others, 1993) and covers more than 14,000 square miles (approximately $36,000 \mathrm{~km}^{2}$ ), is still (2013) an area of active exploration. Since the 1960s, numerous overview studies of the geology, geochemistry, and ore genesis have resulted in an immense body of published research. Important publications include Titley and Hicks (1966), Lowell and Guilbert (1970), and Titley (1983, 1993), who

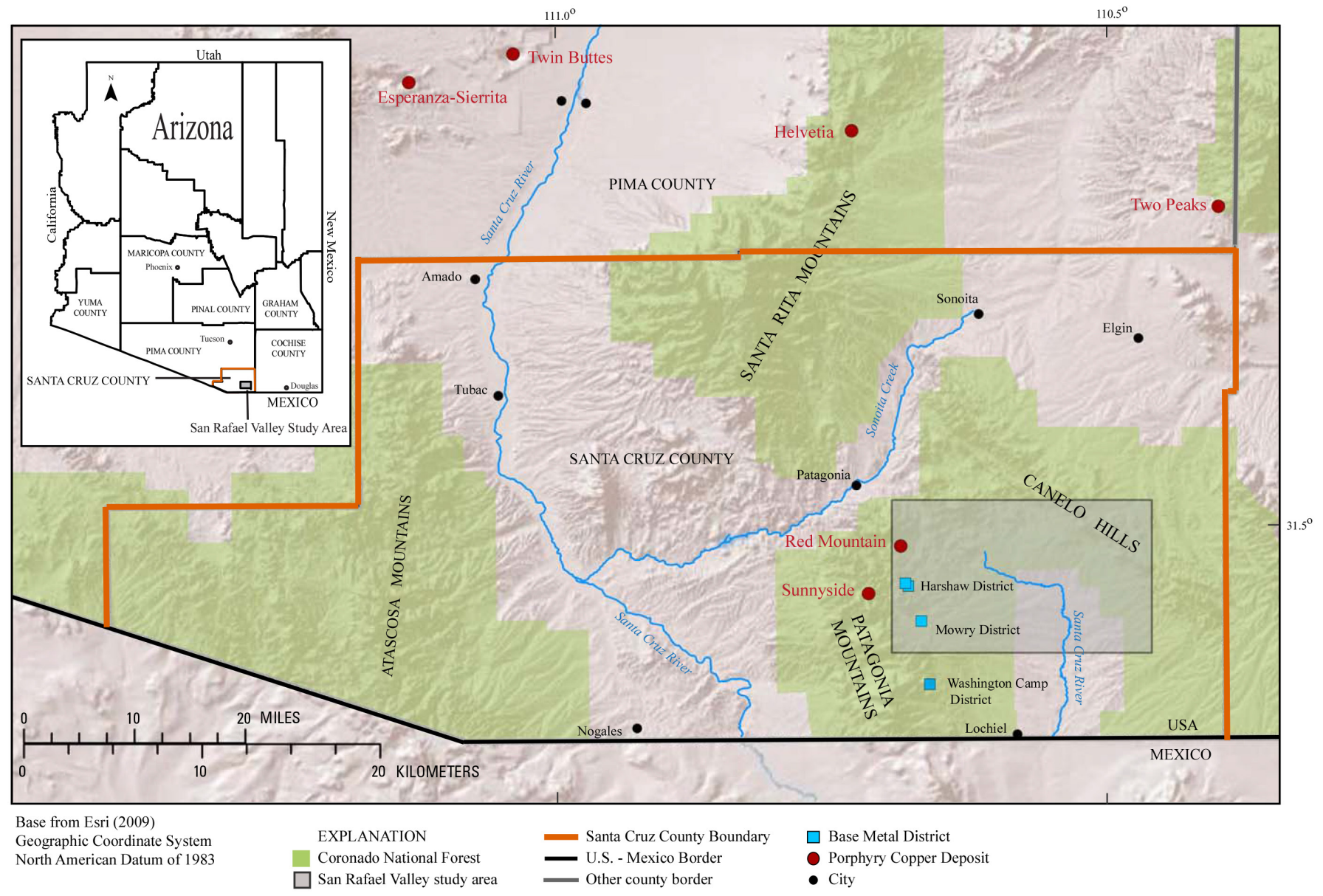

Figure 1. Index map of the San Rafael Valley, Santa Cruz County, Arizona. 


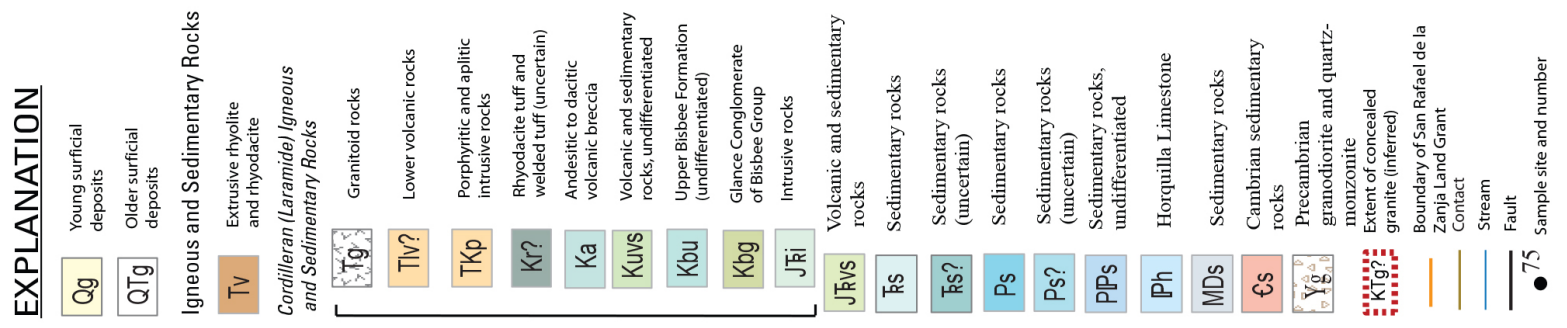

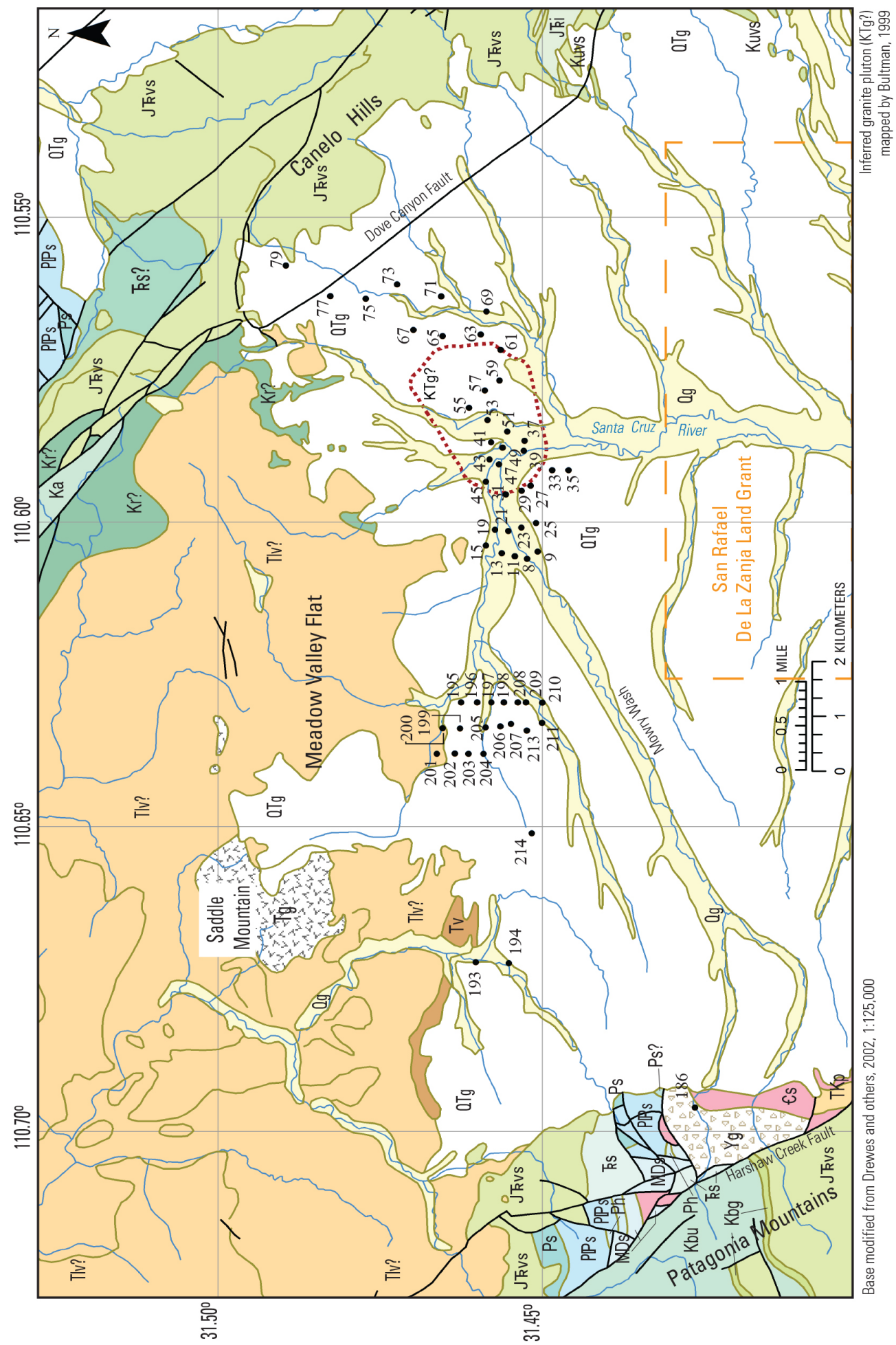

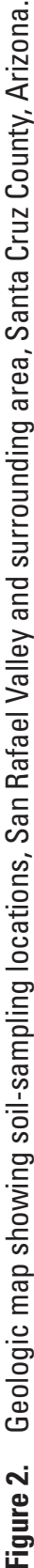


Geochemistry of soils from the San Rafael Valley, Santa Cruz County, Arizona

developed the first porphyry copper deposit models. Corn (1975) and Graybeal (1996) describe (respectively) the Red Mountain and Sunnyside porphyry copper deposits, with which the geochemical signatures observed within the study area were compared, located in the Patagonia Mountains.

Mining in the Patagonia Mountains began prior to the U.S. Civil War, but it was not until the 1880s (Bird, 1916) that the mining operations increased production and invested in on-site processing plants. There are more than 100 mines and prospects in the Patagonia Mountains (Graybeal, 1984), where the principal commodities are lead and silver with some copper, gold, molybdenum, and zinc (fig. 3). Mining in the area ceased in 1959 with the closure of the Flux Mine (Graybeal, 1984). Discovery of a porphyry copper deposit at Red Mountain (Corn, 1975) in the 1970s has led to renewed exploration in the Patagonia area; however, as of 2013 the Red Mountain deposit is not yet in production.

Mining activity in the Canelo Hills to the east of the valley began in the 1880 s with the discovery of oxidized silver, copper, and gold ores. Schrader and Hill (1915) and Bird (1916) described many of the mines and prospects operating at the turn of the 20th century in the mining districts of the Canelo Hills and Patagonia Mountain areas. All of these mines are now closed.

In 1996, the USGS published a mineral-resource assessment of the Coronado National Forest (du Bray, 1996) that identified tracts of land considered to be favorable for the occurrence of various mineral deposits. The assessment includes chapters on geology (Drewes, 1996); geochemistry (Nowlan, 1996); aeromagnetic, radiometric, and gravity data (Gettings, 1996); remote sensing (Bultman, 1996); and mineral-resource data (Drewes and Bultman, 1996; Bultman and Drewes, 1996). The report is the most complete compilation of mineral-resource data for the region and was used as a framework for the current study in the San Rafael Valley.

The Patagonia Mountains and the northernmost parts of the San Rafael Basin have high and moderate potential, respectively, for undiscovered porphyry copper skarn, polymetallic replacement, tungsten vein, and tungsten skarn deposits (Bultman and Drewes, 1996). In the Patagonia and Canelo Mountains, the favorable rocks for the formation of ore deposits are mainly lower Paleozoic and upper Cretaceous to lower Tertiary andesitic to dacitic volcanic and volcaniclastic rocks (Tlv?, Tlv; Drewes and Bultman, 1996). These units crop out in Meadow Valley Flat in the northern part of the basin, and are projected to underlie the Tertiary and Quaternary-Tertiary alluvium (QTg) present in the central part of the San Rafael Basin (Bultman, 1999).

The location of the geophysical anomaly first identified by Gettings (1996) during the Coronado National Forest mineralresource assessment (du Bray, 1996) was further defined by Bultman (1999). Gettings (1996) inferred from gravity data that the San Rafael Basin is shallow - no more than 300 to $500 \mathrm{~m}$ deep — and that much of the underlying bedrock is an extension of the Santa Rita Mountains units (located northwest of the study area in figure 2). Bultman (1999) later collected geophysical data along five transects through the San Rafael Valley with a truck-mounted magnetometer. He identified an area whose magnetic signature resembles that of a granitic body with a skarn halo surrounding it that is buried beneath an approximately 100 -m thickness of basin fill. This inferred granite is the focus of this geochemical survey and is outlined with a reddish-brown dotted line in the figures in this report.

The geologic base map used in this report was derived from the digital map of the area compiled by Drewes and others (2002) and Drewes (1996), and was modified to show only the study area. Mine and prospect locations and mineral information were collected from the USGS Mineral Resources Data System (U.S. Geological Survey, 2010).

\section{Sample Collection and Geochemical Analysis}

All of the soil samples (locations shown in figure 2) were collected from Quaternary-Tertiary gravel, sand, and conglomerate alluvium of Holocene to Miocene age (QTg) and from Quaternary gravels (Qg), which are the younger surficial deposits of gravel, sand, and silt alluvium of Holocene to Pleistocene age (Bultman, 1999). These basin-fill sediments are derived from the erosion and transport of rocks and minerals from surrounding areas and not from bedrock directly underlying the sample location. Samples were collected at a depth interval of 10 to $30 \mathrm{~cm}$ below the surface. The depth interval and geochemical analysis results for each sample site are listed in table 1. The two methods of geochemical analysis, inductively coupled plasmamass spectrometry (ICP-MS) and Mobile Metal Ion ${ }^{\mathrm{TM}}(\mathrm{MMI})$, required different methods of sample preparation and digestion prior to analysis. Initially, the bulk sample was split into two parts at the SGS laboratory (Toronto, Ontario). All sample splits were passed through a 5-millimeter-aperture sieve to remove large rocks and roots. No further size separations were made for the sample splits to be analyzed for 53 elements by $\mathrm{MMI}^{\mathrm{TM}}$. The sample splits to be analyzed for 50 elements by ICP-MS were passed through a 100-mesh (150-micrometer) sieve.

Samples analyzed by ICP-MS were treated with a sequential multi-acid digestion of hydrochloric acid ( $\mathrm{HCl})$, nitric acid $\left(\mathrm{HNO}_{3}\right)$, hydrofluoric acid $(\mathrm{HF})$, and perchloric acid $\left(\mathrm{HClO}_{4}\right)$, resulting in a near-total dissolution of all mineral material (SGS, 2009a). The solute was analyzed for Ag, Al, As, Ba, Be, Bi, Ca, Cd, Ce, Co, Cr, Cs, Cu, Fe, Ga, Ge, Hf, In, K, La, Li, Lu, Mg, Mn, Mo, Na, Nb, Ni, P, Pb, Rb, S, Sb, Sc, Se, Sn, Sr, Ta, Tb, Te, Th, Ti, Tl, U, V, W, Y, Yb, Zn, and Zr. The lower limits of detection are listed by element in table 2 . Elements determined by this method are listed in table 1 with "ICP" appended to the 


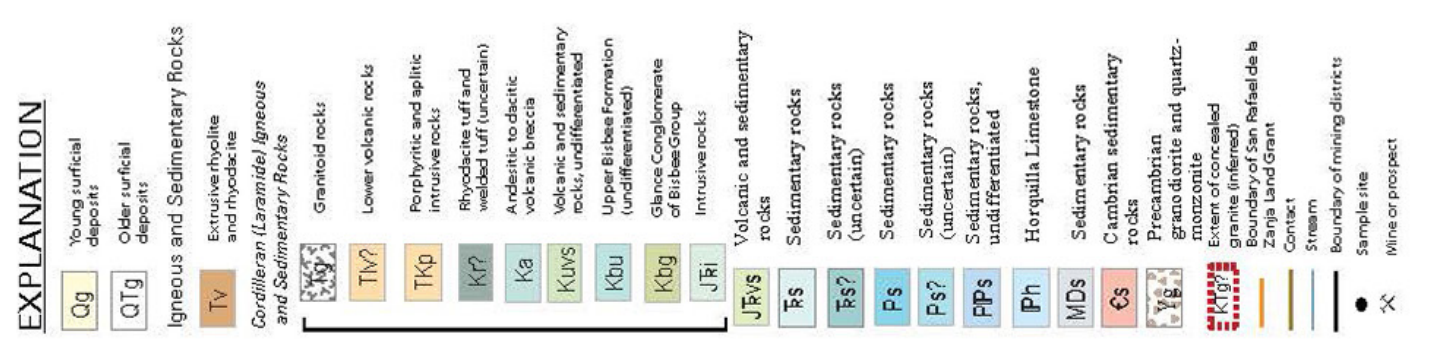

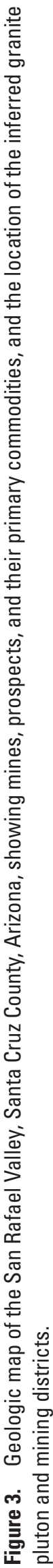

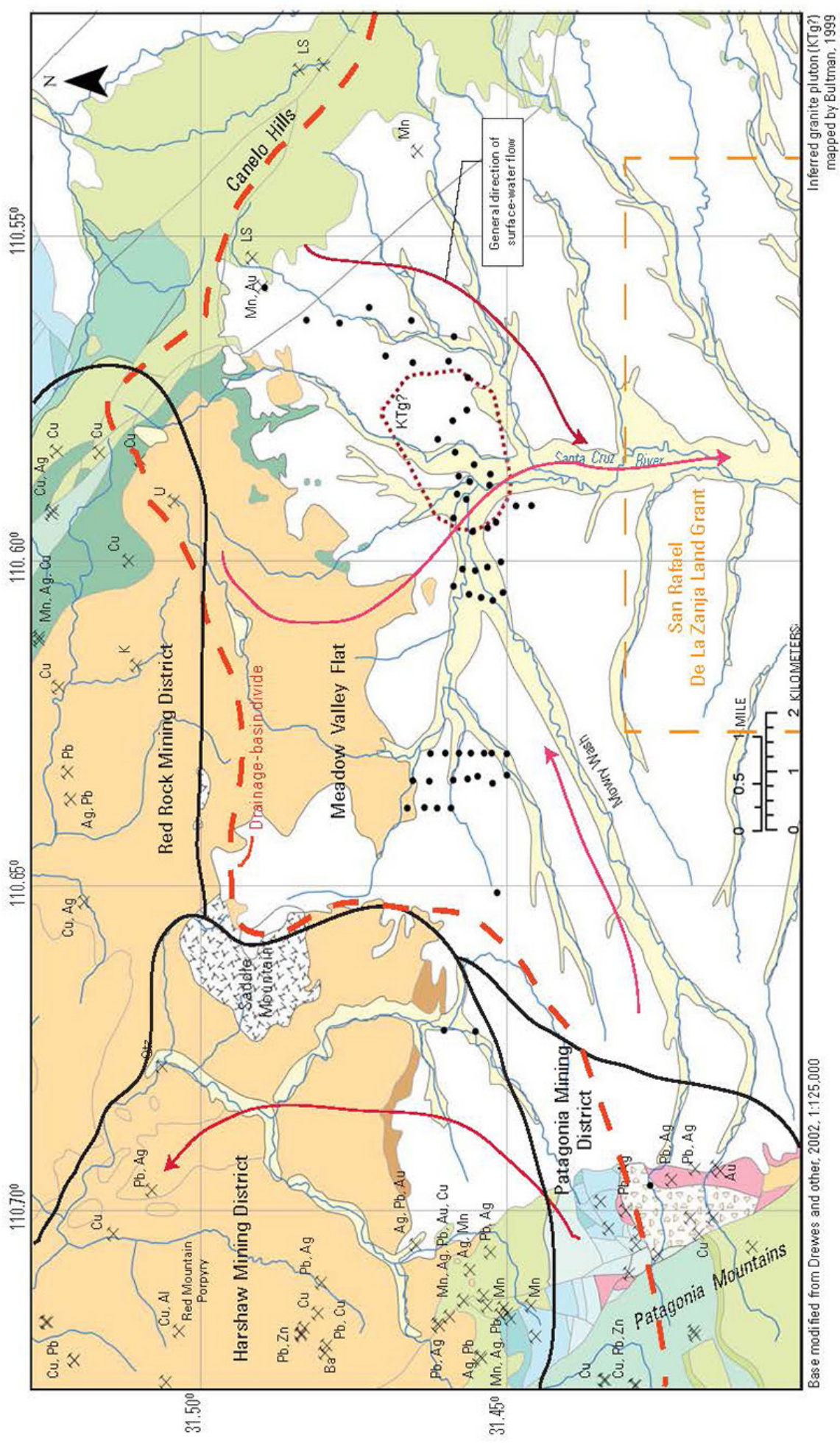


Geochemistry of soils from the San Rafael Valley, Santa Cruz County, Arizona

element name—-for example, Zn_ICP_ppm. Concentrations are in units of parts per million (ppm), parts per billion (ppb), or percent (pct).

Samples analyzed by MMI ${ }^{\mathrm{TM}}$ were not digested in acids; instead, the process strips only the "weakly attached" ions from the soil through the application of weak solutions of inorganic and organic compounds (SGS, 2009b). The premise of this method is that metal ions released from oxidizing mineral deposits travel vertically through the soil column to a point where they remain as unbound metal ions reflecting the characteristics of underlying rocks (Mann and others, 2005). The $\mathrm{MMI}^{\mathrm{TM}}$ solute was analyzed by ICP-MS for Ag, Al, As, Au, Ba, Bi, Ca, Cd, Ce, Co, Cr, Cs, Cu, Dy, Er, Eu, Fe, Ga, Gd, Hg, In, K, La, Li, Mg, Mn, Mo, Nb, Nd, Ni, P, Pb, Pd, Pr, Pt, Rb, Sb, Sc, Sm, Sn, Sr, Ta, Tb, Te, Th, Ti, Tl, U, W, Y, Yb, Zn, and Zr. The lower limits of detection are listed by element in table 2. Elements determined by this method are listed in table 1 with "M" appended to the element namefor example, Zn_M_ppb. Concentrations are in units of parts per million or parts per billion. Samples not analyzed for a particular element are listed as "NA."

Summary statistics were computed for each element and listed by method of analysis. The results are shown in table 3 . Each element, together with the method of analysis and reporting unit, is listed in the "Element" field. The "Min" and "Max" are the lowest and highest detected values, respectively, measured in the study. The arithmetic mean and standard deviation were calculated only on the valid responses (Valid) and do not include less-than (LT) or not-analyzed (NA) responses. The detection ratio (DR) is the ratio of the number of valid responses to the total number of samples analyzed, and is expressed as a percentage. This ratio can be used to quickly assess the proportion of sample analyses that fall above the detection limit. For a few samples, an element was not determined; in those cases, "NA" (not analyzed) is shown in place of the concentration of the unmeasured element. The percentiles were calculated on the entire dataset (excluding NAs). In cases where some samples had less than detectable concentrations, the percentile value is noted by an "N" preceded by the limit of detection for that element. For example, the percentiles for AS_MMI_PPB indicate that 50 percent of the samples had concentrations less than the detection limit of $10 \mathrm{ppb}(10 \mathrm{~N})$. An asterisk $\left(^{*}\right)$ in any field means that a value could not be computed. Se_ICP_PPM, Cr_MMI_PPB, Hg_MMI_PPB, Pt_MMI_PPB, Sn_MMI_PPB, and Te_MMI_PPB were omitted from table 3 because concentrations were not greater than the detection limit.

\section{Geochemistry of Soils}

Geochemical patterns and anomalies in soils, sediments, and rocks have become diagnostic criteria for mineral exploration. During the process of pluton emplacement and ore formation, circulating hydrothermal fluids can produce dispersion aureoles of extensive geochemical anomalies surrounding these bodies. The elevated concentrations of trace elements associated with certain types of deposits are known as "pathfinder elements," which have been used successfully to develop exploration targets. Lowell and Guilbert (1970), who examined the mineralogy and geology of 27 major porphyry copper deposits, recognized concentric and sometimes overlapping zones of alteration and mineralization. These observations led to the development of a model for the lateral and vertical zoning of a "typical" porphyry copper deposit. In the idealized model, successive zones of mineralization may be present, from a low-grade core of chalcopyrite, pyrite, and molybdenite, to an ore shell of 1 percent pyrite, 1 to 3 percent chalcopyrite, and 0.03 percent molybdenite, to a pyrite shell ( 2 percent pyrite) and the outermost peripheral zone of chalcopyrite, galena, sphalerite, Au, and Ag (Lowell and Guilbert, 1970). Overlapping these mineralized zones are zones of potassic, argillic, sericitic, and propylitic hydrothermal alteration (from the center outward). Corn (1975) and Graybeal (1984) described similar zones of enrichment and alteration at the Red Mountain and Sunnyside porphyry copper deposits, respectively, in the Patagonia Mountains.

Stream-sediment samples collected from the Red Mountain, Saddle Mountain, and Patagonia Mountains drainages by Nowlan (1996) and Chaffee and others (1981) contained anomalous concentrations of Ag, As, $\mathrm{Au}, \mathrm{Ba}, \mathrm{Bi}, \mathrm{Cd}, \mathrm{Cu}, \mathrm{Mn}, \mathrm{Mo}, \mathrm{Pb}$, $\mathrm{Sb}, \mathrm{Sn}, \mathrm{W}$, and $\mathrm{Zn}$. They concluded that the elevated concentrations of these metals most likely are associated with replacement and porphyry copper type deposits of the Patagonia (Mowry) and Harshaw Districts (fig. 3). Many of these same elements are found in the soils of streambeds draining these mining districts, indicating that the stream drainages may be active pathways for the transport of ore minerals and metals from the mineralized areas upstream and whose geochemical signature is easily distinguished in the geochemical results of this study.

Statistical analysis with principal components and factor- and cluster-analysis methods (Davis, 1986) were applied to results of both geochemical methods for the soils overlying and near the inferred granite. The ICP-MS geochemistry and correlation analyses tend to more closely reflect characteristics of the surrounding lithologies because the entire soil sample is completely digested prior to analysis. The $\mathrm{MMI}^{\mathrm{TM}}$ results are more likely to represent the correlations of the elements adsorbed on the surfaces of colloidal particles, clays, Fe-Mn oxides, and organic materials. 


\section{Spatial Analysis by Element}

Although copper is arguably the most sought-after commodity in the southwestern United States, the ICP-MS copper concentrations were highest (114 and $93.7 \mathrm{ppm}$ ) in samples from the soils and sediments collected closest to the Tertiary volcanic (Tlv?) rocks of the Meadow Valley Flat, relatively low in those from the Mowry Wash, and only slightly higher in those collected over the inferred granite intrusion (fig. A1). The highest MMI ${ }^{\mathrm{TM}}$ copper value (2.59 ppm) was in a sample from the Mowry Wash (fig. A2). Plots of the concentrations of individual elements were constructed for a suite of elements that are of particular interest in porphyry copper exploration. The thematic maps in appendix A show the distribution of these elements and their concentrations ranked by percentile. These elements include molybdenum (fig. A3, A4), calcium (fig. A5, A6), iron (fig. A7, A8), sulfur (fig. A9), potassium (fig. A10), manganese (fig. A11), and zinc (fig. A12). Although one would expect that iron, sulfur, and potassium would be enriched near a porphyry copper deposit (John and others, 2010), it is apparent that these elements are not enriched in the area of the inferred pluton. In the ICP-MS analyses, copper and molybdenum concentrations were only slightly enriched in soils collected west of the inferred pluton, and the $\mathrm{MMI}^{\mathrm{TM}}$ samples indicate a possible correlation with the drainages from the Patagonia Mountains. No single element stands out as anomalous in the vicinity of the buried inferred pluton.

\section{Principal Component Analysis (PCA)}

Principal component analysis (PCA) (Davis, 1986) was used to calculate component scores and factor loadings from a correlation matrix with a varimax rotation by using Systat 13 (Systat Software, Inc.). The program standardizes the raw data before converting them into a component score. The component scores have the equivalent of the standard normal form with a zero mean and variable concentrations expressed in units of standard deviation. Elements that have high component loadings (loading values greater than the absolute value of 0.5 ) have high relative importance within that component. The importance of the component is determined by how much of the total variance is explained by the component (tables 4 and 5). In order to better visualize the correlations between the factors and the underlying geology, thematic maps of the component scores for each of the eight components were constructed by using ArcGIS (Esri; www.esri.com) (fig. B1-B8; fig. C1-C7). The scores were divided into five classes according to rank, from lowest correlation (dark blue) to highest correlation (red), by using Jenks Natural Breaks (ArcMap ${ }^{\mathrm{TM}}$ 10) (Esri; www.esri.com). Each figure shows the range of component scores.

Before PCA was conducted, all concentration values for the soils analyzed by ICP-MS were log-transformed in order to improve the statistical analysis by more closely approximating a normal distribution. ICP-MS concentrations reported as less than the lower limits of detection were replaced by one-half the lower limit of detection for that element. The principal components for ICP-MS geochemistry were calculated on 58 samples and 50 elements. Thematic maps of the component scores for the ICP-MS results are shown in appendix B (fig. B1-B8).

$\mathrm{The} \mathrm{MMI}^{\mathrm{TM}}$ analytical results differ from the ICP-MS results in that the concentrations are much smaller (generally in the parts-per-billion range) and include more qualified (less than the detection limit) values. Therefore, in an effort to minimize the bias introduced by the qualified values, the $\mathrm{MMI}^{\mathrm{TM}}$ data were transformed into response ratios before factor analysis was conducted. The response ratio (Mann and others, 2005) for each element is calculated by (1) replacing all qualified values with one-half the detection limit, (2) calculating the average value of the lower 25th percentile (which becomes the background value), (3) normalizing the data by dividing each analytical value by the background value, and (4) rounding up the final value to one decimal place. Principal components were then calculated on the log-transformed response ratios for 38 variables for 58 samples. The elements Cs, Ga, In, K, Mn, and P were omitted from the analysis because they were measured in only half the samples collected; $\mathrm{Cr}, \mathrm{Hg}, \mathrm{Pt}, \mathrm{Sn}$, and Ta were omitted because there were no detectable concentrations of these elements; and $\mathrm{Bi}, \mathrm{Nb}, \mathrm{Pd}$, and Te were omitted because detectable concentrations were measured in fewer than 20 percent of the samples (DR $<20$ ). The variables included are Ag, Al, As, Au, Ba, Ca, Cd, Co, Cu, Fe, Li, Mg, Mo, Ni, Pb, Rb, Sb, Sc, Sr, Th, Ti, Tl, U, W, Y, $\mathrm{Zn}, \mathrm{Zr}$, and rare earth element lanthanides $\mathrm{Ce}, \mathrm{Dy}, \mathrm{Er}, \mathrm{Eu}, \mathrm{Gd}, \mathrm{La}, \mathrm{Nd}, \mathrm{Pr}, \mathrm{Sm}, \mathrm{Tb}$, and $\mathrm{Yb}$. Thematic maps of the MMI ${ }^{\mathrm{TM}}$ factor scores based on the response ratio for each element are shown in appendix C (fig. C1-C7).

The results show that elements that have high factor loadings for a particular factor group together into one of seven or eight factors. The number of factors used in the analysis was determined by the break in the scree slope and an eigenvalue greater than 1. Plotting the component scores for each soil sample allows us to examine which variables are related to others by their measures of similarity (positive scores) and dissimilarity (negative scores). Factor scores can be used to identify important mineral sources of elements or processes that influence their concentrations. Possible interpretations of these factor scores are discussed below.

The ICP-MS-derived factors (table 4) fall into eight groups of elements. Factor 1 ( $\mathrm{Yb}, \mathrm{Y}, \mathrm{Tb}, \mathrm{Lu}, \mathrm{Be}, \mathrm{Ce}, \mathrm{Co}$, and $\mathrm{La}$ ) is dominated by light rare earth elements (LREEs), which tend to occur together in trace amounts in accessory minerals (such as monazite, xenotime, euxenite, etc.) of igneous rocks. Small accumulations of these LREE-bearing minerals, possibly derived from the igneous rocks upstream as well as from the underlying alluvial units, may explain the spotty occurrences of high 
factor scores in the study area. Factor 2 consists of trace metals (In, Pb, Bi, Ag, Te, Zn, Cd, and Mo) that represent a hydrothermal mineralization signature. They are most likely associated with the argentiferous lead ores from the fissure-vein and replacement deposits in the Patagonia and Harshaw Mining Districts. The primary ore minerals noted at the Mowry Mines are cerussite $\left(\mathrm{PbCO}_{3}\right)$, coarse galena $(\mathrm{PbS})$, anglesite $\left(\mathrm{PbSO}_{4}\right)$, bindheimite $\left(\mathrm{Pb}_{2} \mathrm{Sb}_{2} \mathrm{O}_{6}(\mathrm{O}, \mathrm{OH})\right)$, and malachite $\left.\left(\mathrm{Cu}_{2} \mathrm{CO}_{3}\right)(\mathrm{OH})_{2}\right)$ with psilomelane $\left(\left(\mathrm{Ba}, \mathrm{H}_{2} 0\right)_{2} \mathrm{Mn}_{5} \mathrm{O}_{10}\right)$, massive pyrolusite $\left(\mathrm{MnO}_{2}\right)$, and hematite $\left(\mathrm{Fe}_{2} \mathrm{O}_{3}\right)$ gangue (Schrader and Hill, 1915). Smaller amounts of chalcopyrite $\left(\mathrm{CuFeS}_{2}\right)$, chalcocite $\left(\mathrm{Cu}_{2} \mathrm{~S}\right)$, and sphalerite $(\mathrm{ZnS})$ are present in some mines. The soils with the highest factor scores occur along the streambeds of streams that drain these mining districts. Factor 3 (Hf, $\mathrm{Ti}, \mathrm{Zr}, \mathrm{Cu}, \mathrm{Ni}, \mathrm{Al}, \mathrm{Fe}, \mathrm{S}, \mathrm{Sc}$, $\mathrm{Li}, \mathrm{P}, \mathrm{Mo}$, and $\mathrm{U}$ ) consists of a suite of elements that are commonly found in resistate minerals (apatite, zircon, rutile, titanite, pyrite, etc.) that occur in many rock types. High factor scores may be associated with the accumulation of these heavy minerals in the soils. The highest factor scores appear to group near outcrops of Tertiary volcanic rocks (Tlv?), where these resistate minerals may have been shed into the alluvium and stream drainages. Factor 4 ( $\mathrm{Ta}, \mathrm{Nb}, \mathrm{W}, \mathrm{Sb}$, and $\mathrm{Sn}$ ) elements are commonly associated with granitic rocks and metasomatic skarns; these elements are slightly soluble with low mobility in soils. Factor scores are highest overlying and adjacent to the Tlv? and occur at concentrations typical for the range of soils derived from granitic source rocks (Kabata-Pendias and Pendias, 1992).

Factor 5 elements (As and -Th) identified a negative correlation where arsenic (As) concentration is high and thorium (Th) concentration is low. This inverse relation may reflect two prominent processes of element accumulation. Arsenic, which occurs in many mineral forms, is readily soluble and easily sorbed by clays, hydroxides, and organic matter. Thorium is commonly found in the mineral monazite, a heavy mineral found as an accessory mineral in felsic igneous rocks. This factor may indicate sites where small accumulations of monazite (blue symbols in figure B5) occur and where arsenic-sorbed clays are lacking and vice versa (red symbols in figure B5). Factor 6 includes $\mathrm{Na}, \mathrm{Sr}, \mathrm{Ba}$, and $\mathrm{Mn}$. These elements are commonly associated with alkali feldspars, which may have been transported as detrital grains along stream drainages from igneous source rocks upstream. Higher factor scores appear to be associated with the Mowry Wash and the central confluence of the headwaters of the Santa Cruz River. Factor 7 includes Cs, Ga, Cr, Be, and V. These elements, common in trace amounts in feldspars and micas of igneous rocks, are easily sorbed by clays once released by weathering (Kabata-Pendias and Pendias, 1992). The samples with the highest factor scores are found near the central portion of the Santa Cruz drainage, where argillaceous sediments would be common. High factor $8(\mathrm{~K}, \mathrm{Rb}, \mathrm{Tl}$, and $\mathrm{Sb})$ scores appear to be randomly dispersed and may represent the accumulation of potassic feldspars in the alluvium.

The $\mathrm{MMI}^{\mathrm{TM}}$-derived factors (table 5) fall into seven groups that are statistically correlated; however, their element members generally differ from those of the ICP-MS-derived factors. Whereas the ICP-MS factor scores are related to the mineralogy of the soil, the $\mathrm{MMI}^{\mathrm{TM}}$ factor scores are related to the $\mathrm{Mn}, \mathrm{Fe}$, and $\mathrm{Al}$ oxides and hydroxides, clays, and humic substances and the elements adsorbed to them. Factor 1 elements (Tb, Gd, Eu, Dy, Sm, Y, Er, Nd, Yb, Ce, Pr, La, Sc, Th, Zr, U, Al, and Rb) are commonly enriched in soils derived from granite and volcanic rocks. The distribution of high factor scores appears to be scattered and may reflect a heavy mineral signal of the alluvium. The highest factor $2(\mathrm{Mg}, \mathrm{Sr}, \mathrm{Ni}, \mathrm{Ca}, \mathrm{Li}$, and $\mathrm{Cu})$ scores appear along stream channels that drain the volcanic rocks (Tlv?) to the north and west of the inferred granite (KTg?). These alkaline earth elements may reside in or be adsorbed to carbonate or clay minerals present in the soil. The distribution of high factor 3 ( $\mathrm{Zn}, \mathrm{Cd},-\mathrm{Ba}$, and -Co) scores mirrors the distribution of high ICP-MS-derived factor scores of similar elements (shown in figure B2) and are most likely related to the dissolution and weathering of ore minerals transported from the deposits in the Patagonia and Harshaw Mining Districts. Factor 4 element ( $\mathrm{Sb}, \mathrm{Fe}$, and W) scores appear to be highest near the confluence of the Mowry Wash and the Santa Cruz River. There may be several sources of Sb and W, which can be very mobile in the environment and become adsorbed by Fe hydroxides and oxides in the soil (Kabata-Pendias and Pendias, 1992). It is not unusual to find factor 5 elements $(\mathrm{Ag}, \mathrm{Au}$, and $\mathrm{Pb})$ together, most likely as the result of weathering of the argentiferous ore minerals released in trace amounts and adsorbed to $\mathrm{Mn}$ and Fe oxides in the soils. The distribution of high factor 5 scores seems to correlate well with the Ag associated with the Mowry Wash (observed in figure B2). Koutz (1984) reported 6.7 ounces (oz) per ton (209 grams (g) per metric ton) Ag, $0.008 \mathrm{oz} /$ ton $(0.25 \mathrm{~g} /$ metric ton $) \mathrm{Au}$, and 1.8 percent $\mathrm{Pb}$ in manto type ores from the Hardshell deposit in the Harshaw District to the north of the Mowry District. Factor 6 (Mo) scores are highest in soils along the Mowry Wash and near its confluence with the Santa Cruz River. This element may have been retained in the organic material and Fe hydroxides. The mineral wulfenite $\left(\mathrm{Pb}\left(\mathrm{Mo}_{4}\right)\right)$ was identified in the deposits in the Mowry District (Schrader and Hill, 1915) and may be a source material. Factor 7 (Ti) scores are highest on the western slope of the Canelo Hills and to the west of the inferred granite, and most likely are associated with the accumulation of resistate minerals (ilmenite, titanite, rutile, anatase, etc.) in the soil profile.

\section{Cluster Analysis}

K-Means cluster analysis was used to partition the ICP-MS and MMI ${ }^{\mathrm{TM}}$ soil-chemistry data for 11 variables into a small set of groups (clusters) that are most similar in chemical characteristics (Davis, 1986). Variables that are grouped together typically reflect distinctive rock sources or depositional settings. The K-Means cluster analysis was conducted on log-transformed 
ICP-MS (for $\mathrm{Ag}, \mathrm{As}, \mathrm{Cu}, \mathrm{Fe}, \mathrm{Mo}, \mathrm{Pb}, \mathrm{Sb}, \mathrm{W}$, and $\mathrm{Zn}$ ) and $\mathrm{MMI}^{\mathrm{TM}}$ (for $\mathrm{Ag}, \mathrm{Au}, \mathrm{Cu}, \mathrm{Fe}, \mathrm{Mo}, \mathrm{Pb}, \mathrm{Sb}, \mathrm{W}$, and $\mathrm{Zn}$ ) results using $\mathrm{JMP}^{\circledR}$ (version 10) software (SAS Institute Inc.; www.sas.com). Analytical results reported as less than the detection limit were replaced with a value of one-half the detection limit prior to logarithmic transformation. No stream-sediment sample results were used in this analysis. Clusters having an eigenvalue greater than 1.0 were used in the final analysis (see Davis (1986) for a description of cluster analysis). Biplots of the cluster groupings and principal component rays are presented adjacent to thematic maps showing the distribution of the samples by cluster group (figs. D1-D3). The results of cluster analysis of the ICP-MS analyses show four spatial groups: 1, Mowry Wash; 2, undifferentiated alluvium; 3, Canelo Hills; and 4, Meadow Valley drainage. The results of cluster analysis of the $\mathrm{MMI}^{\mathrm{TM}}$ analyses show four cluster groups: 1, Mowry Wash; 2 and 3, undifferentiated alluvium; and 4, Canelo Hills. The Meadow Valley soils are not distinguished by this method. The biplots and the principal component rays indicate that $\mathrm{Pb}, \mathrm{Zn}, \mathrm{Ag}$, and Mo strongly influence principal component 1 in both the ICP-MS and MMI ${ }^{\mathrm{TM}}$ biplots.

Cluster analysis was also done on the combined ICP-MS and MMI ${ }^{\mathrm{TM}}$ element analyses listed above to examine how the elements would cluster (fig. D3). The results show five clusters not unlike the clusters found independently in the ICP-MS and $\mathrm{MMI}^{\mathrm{TM}}$ analyses. Cluster 1 identifies the soils that lie along the Mowry Wash, which, again, most likely reflect the mining districts in the Patagonia Mountains. Cluster 2 once again identifies a group of soils on the western flank of the Canelo Hills that appears to have low metals content and a chemical composition that is distinctly different from that of other lithologies in the area. Cluster 3 identifies a single soil, in a drainage from Saddle Mountain, that is uniquely high in Cu and Fe (ICP-MS) concentrations. Although clusters 4 and 5 appear to be distinct on the base map, the biplot shows substantial overlap of the cluster profiles. Cluster 4 soils are located near the confluence of numerous drainages at the head of the Santa Cruz River. Cluster 5 identifies a group of alluvial soils that are near exposed Tertiary volcanic (Tlv?) and granitic (Tg) rocks. Both clusters most likely represent a mixing of various geochemical and minerals sources from the surrounding area and not a unique geochemical signature related to the inferred granite (KTg). The principal component rays show that, for the most part, ICP-MS- and MMI ${ }^{\mathrm{TM}}$ derived elements tend to group by method in the biplot. For both methods, however, $\mathrm{Pb}, \mathrm{Ag}, \mathrm{Zn}, \mathrm{Cu}$, and $\mathrm{Mo}$ are important elements in principal component 1 and are key to distinguishing clusters 1,2, and 3. Cluster groups 4 and 5 are very similar; however, principal component 2 is dominated primarily by Fe, which helps distinguish between cluster 4 and cluster 5 . Cluster 5 soils have greater total $\mathrm{Fe}$ and $\mathrm{Cu}$ concentrations by ICP-MS than cluster 4 soils, and lower Fe and $\mathrm{Cu}$ concentrations by $\mathrm{MMI}^{\mathrm{TM}}$ than cluster 4 soils. This relation is also apparent in figures A7 and A8. The spatial distribution of cluster groups (fig. D3) shows the influence of the surrounding hills as sources of metals, but no unique cluster group occupies the inferred pluton area.

\section{Conclusions}

This study was conducted to document the geochemical signature of the inferred intrusive feature and to determine whether soils in the San Rafael Valley, Santa Cruz County, Arizona, show evidence of mineral enrichment. The geochemical characteristics of soils from the vicinity of the inferred granite intrusive do not appear to exhibit the alteration zoning typical of a porphyry copper system, where a highly pyritic core has anomalously high copper concentrations. There is also no evidence of traceelement enrichment or hydrothermal alteration zoning that would indicate the possibility of a mineralized porphyry system near the inferred granite. Maximum copper concentrations in the study area are 114 (by inductively coupled plasma-mass spectrometry (ICP-MS)) and 2.59 parts per million (by Mobile Metal Ion ${ }^{\mathrm{TM}}$ (MMI) analysis), and these values appear to be more closely associated spatially with the Mowry Wash and Tertiary volcanic rocks in Meadow Valley Flat than with the inferred granite intrusion. The trace-element patterns do not correlate with or surround the inferred granite area; rather, they show a convincing correlation to the stream drainages of the Mowry Wash, Meadow Valley Flat, and Canelo Hills. Although it is clear that mineralized material is being transported into the San Rafael Valley from the surrounding hillsides, the presence of manganese and iron oxides and organic materials in the alluvium may also influence the geochemical character of the soils.

With respect to the possibility of an alteration halo with skarn mineralization associated with the inferred granite, only factor 4 scores from the $\mathrm{MMI}^{\mathrm{TM}}$ analyses are highest near (but are not restricted to) the inferred granite. This observation may reflect Fe and $\mathrm{W}$ mineralization associated with the inferred granite, but it is not conclusive evidence of a skarn. Thematic maps repeatedly point out the influence of the base metals transported from the mines and tailings of the Mowry and Harshaw Mining Districts in the Patagonia Mountains as well as the lithogeochemistry of the granite and volcanic rocks in the Meadow Valley Flat area. A comparison of the two geochemical methods of soil analysis indicates that both probably were able to identify the trace-element signature of the Mowry drainage but that neither was able to identify a geochemical signature related to the inferred pluton.

The presence of mineral material containing $\mathrm{Pb}, \mathrm{Ag}, \mathrm{Cd}$, and $\mathrm{Zn}$ being transported downstream in the Meadow Valley and the Mowry Wash complicates the interpretation of the overall geochemical characteristics of the study area. Factor analysis of both the ICP-MS and MMI ${ }^{\mathrm{TM}}$ results shows distinct links to the mines and deposits from the surrounding hills. Whether because 
the depth of the inferred intrusive was too great or the composition of the overlying alluvium was not conducive to ion diffusion, a clear geochemical signature of the composition of the intrusive feature and (or) possible skarn mineralization is not apparent.

\section{Acknowledgments}

The authors would like to thank Gilpin Robinson and Suzanne Nicholson for their thorough reviews, comments, and suggestions for improving this manuscript, and Dale Simmons, whose editorial finesse helped bring this manuscript to publication.

\section{References Cited}

Bird, A.T., 1916, Resources of Santa Cruz County: University of Arizona Bureau of Mines, County Resource Series No. 1, 27 p.

Bultman, M.W., 1999, Geometry, structure, and concealed lithology of the San Rafael Basin, southeastern Arizona: U.S. Geological Survey Open-File Report 99-399, version 1.0.

Bultman, M.W., 1996, Remote sensing and its use in identification of altered rocks in Coronado National Forest, in du Bray, E.A., ed., Mineral resource potential and geology of Coronado National Forest, southeastern Arizona and southwestern New Mexico: U.S. Geological Survey Bulletin 2083, chap. F., p.130-140.

Bultman, M.W., and Drewes, H., 1996, Mineral resources, ore deposit models, and resource potential of Coronado National Forest-Locatable minerals, in du Bray, E.A., ed., Mineral resource potential and geology of Coronado National Forest, southeastern Arizona and southwestern New Mexico: U.S. Geological Survey Bulletin 2083, chap. G, p. 141-168.

Chaffee, M.A., Hill, R.H., Sutley, S.J., and Watterson, J.R., 1981, Regional geochemical studies in the Patagonia Mountains, Santa Cruz County, Arizona: Journal of Geochemical Exploration, v. 14, p. 135-153.

Corn, R.M., 1975, Alteration-mineralization zoning, Red Mountain, Arizona: Economic Geology, v. 70, p. 1437-1447.

Davis, J.C., 1986, Statistics and data analysis in geology (2d ed.): New York City, New York, J. Wiley \& Sons, 646 p.

du Bray, E.A., ed., 1996, Mineral resource potential and geology of Coronado National Forest, southeastern Arizona and southwestern New Mexico: U.S. Geological Survey Bulletin 2083, 211 p.

Drewes, Harald, 1996, Geology of the Coronado National Forest, in du Bray, E.A., ed., Mineral resource potential and geology of Coronado National Forest, southeastern Arizona and southwestern New Mexico: U.S. Geological Survey Bulletin 2083, chap. B, p. 17-41.

Drewes, H., and Bultman, M.W., 1996, Summary and introduction, in du Bray, E.A., ed., Mineral resource potential and geology of Coronado National Forest, southeastern Arizona and southwestern New Mexico: U.S. Geological Survey Bulletin 2083, chap. A, p. 3-15.

Drewes, H., Fields, R.A., Hirschberg, D.M., and Bolm, K.S., 2002, Spatial digital database for the tectonic map of southeast Arizona: U.S. Geological Survey Miscellaneous Investigations Series Map I-1109, digital database, version 2.0, 38 p., 2 digital map sheets, scale 1:125,000.

Eatherly, C.R., [n.d.], History of San Rafael State Natural Area: accessed August 17, 2010, at http://azstateparks.com/parks/ SARA/history.html.

Gettings, M.E., 1996, Aeromagnetic, radiometric, and gravity data for Coronado National Forest, in du Bray, E.A., ed., Mineral resource potential and geology of Coronado National Forest, southeastern Arizona and southwestern New Mexico: U.S. Geological Survey Bulletin 2083, chap. D, p. 77-101.

Graybeal, F.T., 1984, Metal zoning in the Patagonia Mountains, Arizona, in Wilkins, J., Jr., ed., Gold and silver deposits of the Basin and Range province, western U.S.A.: Arizona Geological Survey Digest, v. 15, p. 187-197. 
Graybeal, F.T., 1996, Sunnyside-A vertically-preserved porphyry copper system, Patagonia Mountains, Arizona: Society of Economic Geologists Newsletter, no. 26, 6 p.

John, D.A., Ayuso, R.A., Barton, M.D., Blakely, R.J., Bodnar, R.J., Dilles, J.H., Gray, Floyd, Graybeal, F.T., Mars, J.C., McPhee, D.K., Seal, R.R., Taylor, R.D., and Vikre, P.G., 2010, Porphyry copper deposit model, chap. B of Mineral deposit models for resource assessment: U.S. Geological Survey Scientific Investigations Report 2010-5070-B, 169 p.

Kabata-Pendias, Alina, and Pendias, Henryk, 1991, Trace elements in soils and plants (2d ed.): Boca Raton, Florida, CRC Press LLC, $365 \mathrm{p}$.

Koutz, F.R., 1984, The Hardshell silver, base-metal, manganese oxide deposit, Patagonia Mountains, Santa Cruz County, Arizona--A field trip guide, in Wilkins, J., Jr., ed., Gold and silver deposits of the Basin and Range province, western U.S.A.: Arizona Geological Society Digest, v. 15, p. 199-217.

Lowell, J.D., and Guilbert, J.M., 1970, Lateral and vertical alteration-mineralization zoning in porphyry ore deposits: Economic Geology, v. 65, no. 4, p. 373-408.

Mann, A.W., Birrell, R.D., Fedikow, M.A.F., and de Souza, H.A.F., 2005, Vertical ionic migration--Mechanisms, soil anomalies, and sampling depth for mineral exploration: Geochemistry: Exploration, Environment, Analysis, v. 5, no. 3, p. 201-210.

National Oceanic and Atmospheric Administration, [n.d.], Yearly rainfall totals across southeast Arizona since 1993: National Weather Service Forecast Office, Tucson, Arizona, accessed March 19, 2013, at http://www.wrh.noaa.gov/twc/climate/ seaz_yearly_rainfall.php.

Natural Resources Conservation Service, 2011, Web soil survey: accessed January 30, 2011, at http://websoilsurvey.nrcs.usda. gov/app/WebSoilSurvey.aspx.

Nowlan, G.A., 1996, Geochemistry of Coronado Forest, in du Bray, E.A., ed., Mineral resource potential and geology of Coronado National Forest, southeastern Arizona and southwestern New Mexico: U.S. Geological Survey Bulletin 2083, chap. C, p. 43-75.

SGS, 2009a, Multi-acid (4-acid) digestions, ICM40B: accessed November 17, 2009, at http://www.sgs.com/en/Mining/ Exploration-Services/Geochemistry/Trace-Elements.aspx.

SGS, 2009b, Mobile Metal Ions (MMI): accessed November 17, 2009, at http://www.geochem.sgs.com/mmi.htm.

Sawyer, M.B., Gurmendi, A.C., Daley, M.R., and Howell, S.B., 1992, Principal deposits of strategic and critical minerals in Arizona: Washington, D.C., U.S. Bureau of Mines, Special Publication, 334 p.

Schrader, F.C., and Hill, J.M., 1915, Mineral deposits of the Santa Rita and Patagonia Mountains, Arizona: U.S. Geological Survey Bulletin 582, $373 \mathrm{p}$.

Titley, S.R., ed., 1982, Advances in geology of the porphyry copper deposits, southwestern North America: Tucson, Arizona, University of Arizona Press, 560 p.

Titley, S.R., 1993, Characteristics of porphyry copper occurrence in the American southwest, in Kirkham, R.V., Sinclair, W.D., Thorpe, R.I., and Duke, J.M., eds., Mineral deposit modeling: Geological Association of Canada Special Paper 40, p. 433-464.

Titley, S.R., and Hicks, C.L., 1966, Geology of the porphyry copper deposits, southwestern North America: Tucson, Arizona, University of Arizona Press, 287 p.

U.S. Geological Survey, 2010, Mineral resources data system (MRDS): Online spatial data, accessed June 1, 2010, at http://tin.er.usgs.gov/mrds/. 


\section{Appendix A. Thematic maps showing sample location and distribution of selected trace elements in soil}

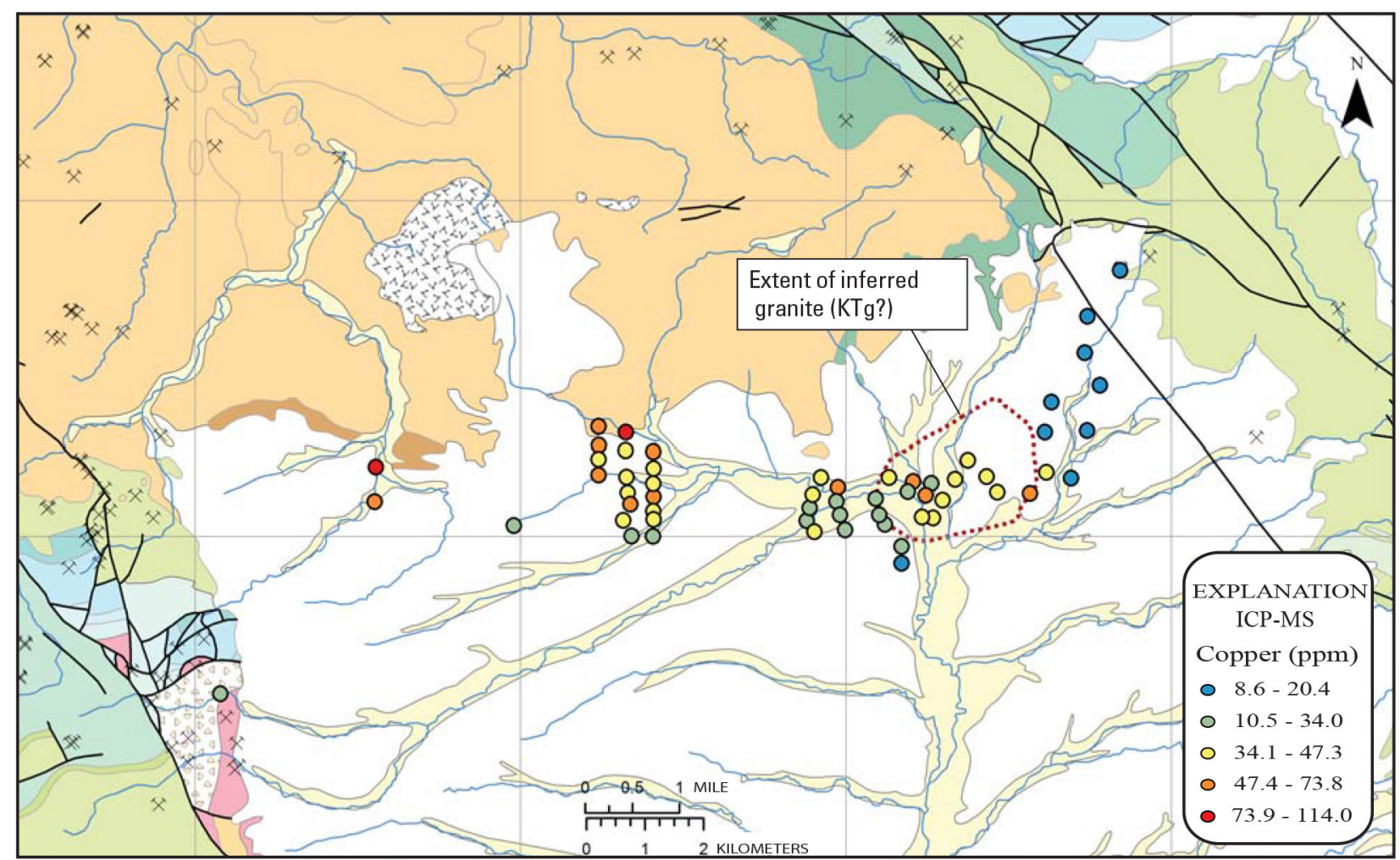

Figure A1. Geologic map of San Rafael Valley, Santa Cruz County, Arizona (described in figures 2 and 3), showing sample location and copper concentrations in parts per million in soil samples analyzed by inductively coupled plasma-mass spectrometry (ICP-MS). 


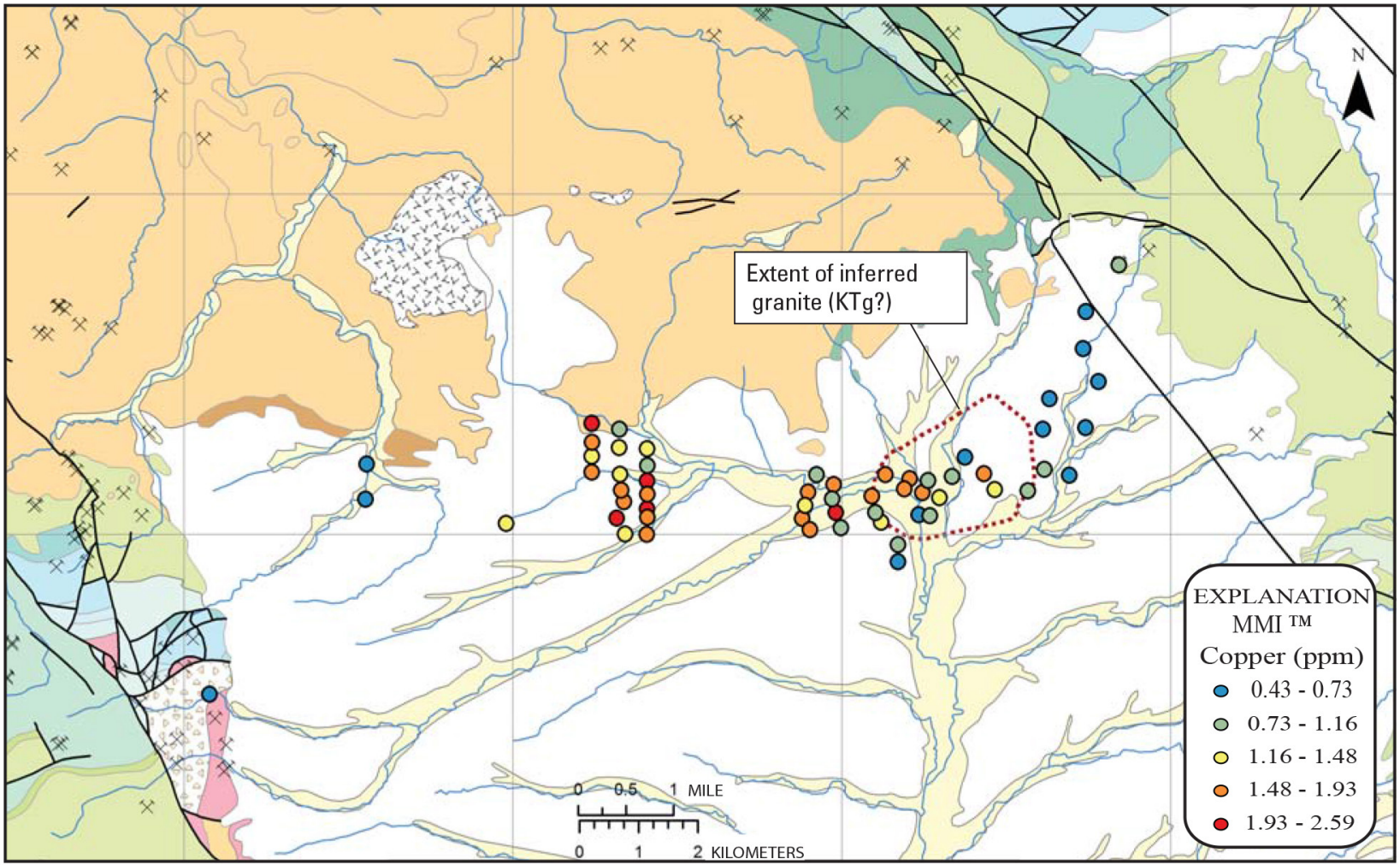

Figure A2. Geologic map of San Rafael Valley, Santa Cruz County, Arizona (described in figures 2 and 3), showing sample location and copper concentrations in parts per million in soil samples analyzed by Mobile Metal lon $\left(\mathrm{MMI}^{\mathrm{TM}}\right)$.

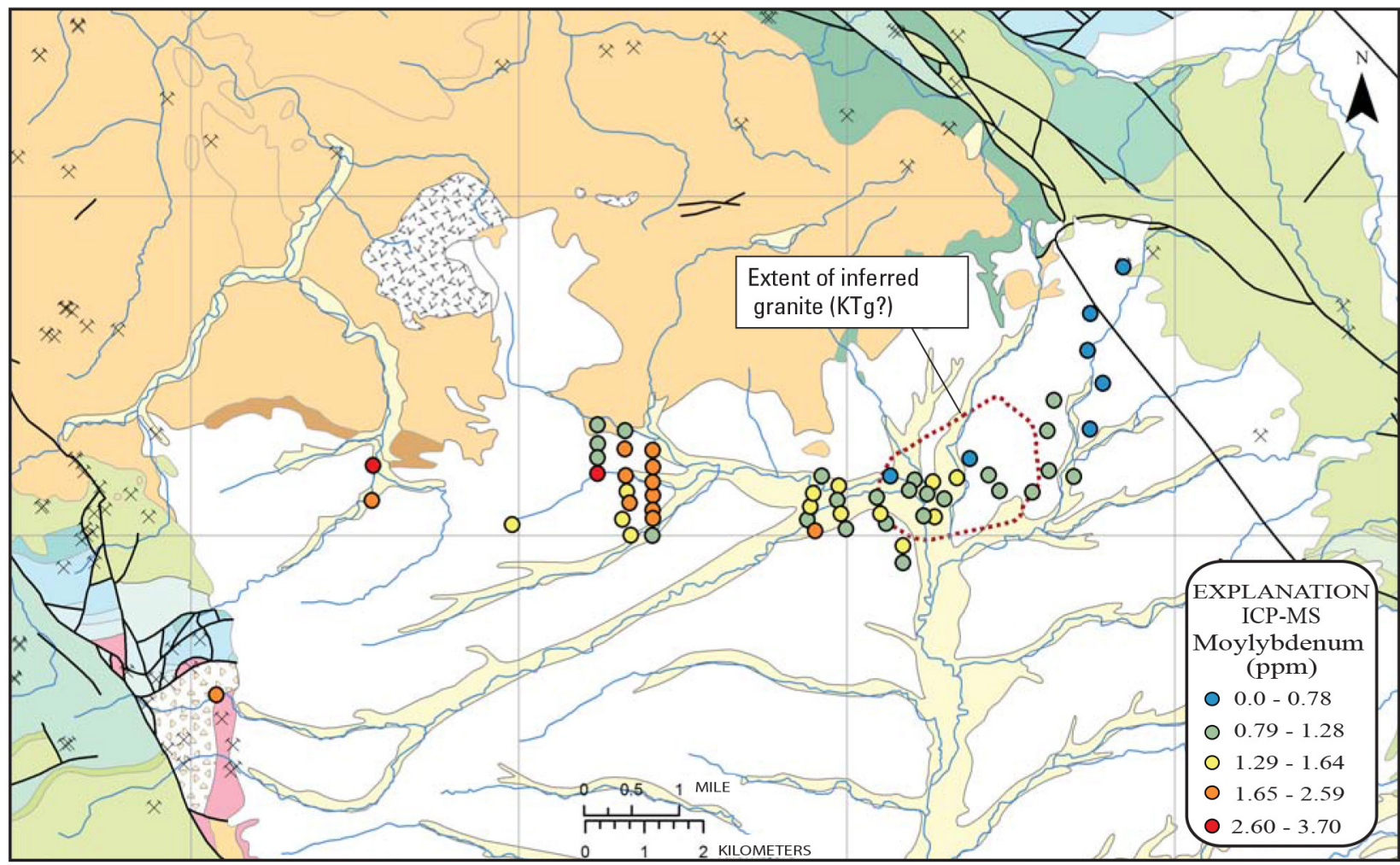

Figure A3. Geologic map of San Rafael Valley, Santa Cruz County, Arizona (described in figures 2 and 3), showing sample location and molybdenum concentrations in soil samples analyzed by inductively coupled plasma-mass spectrometry (ICP-MS). 


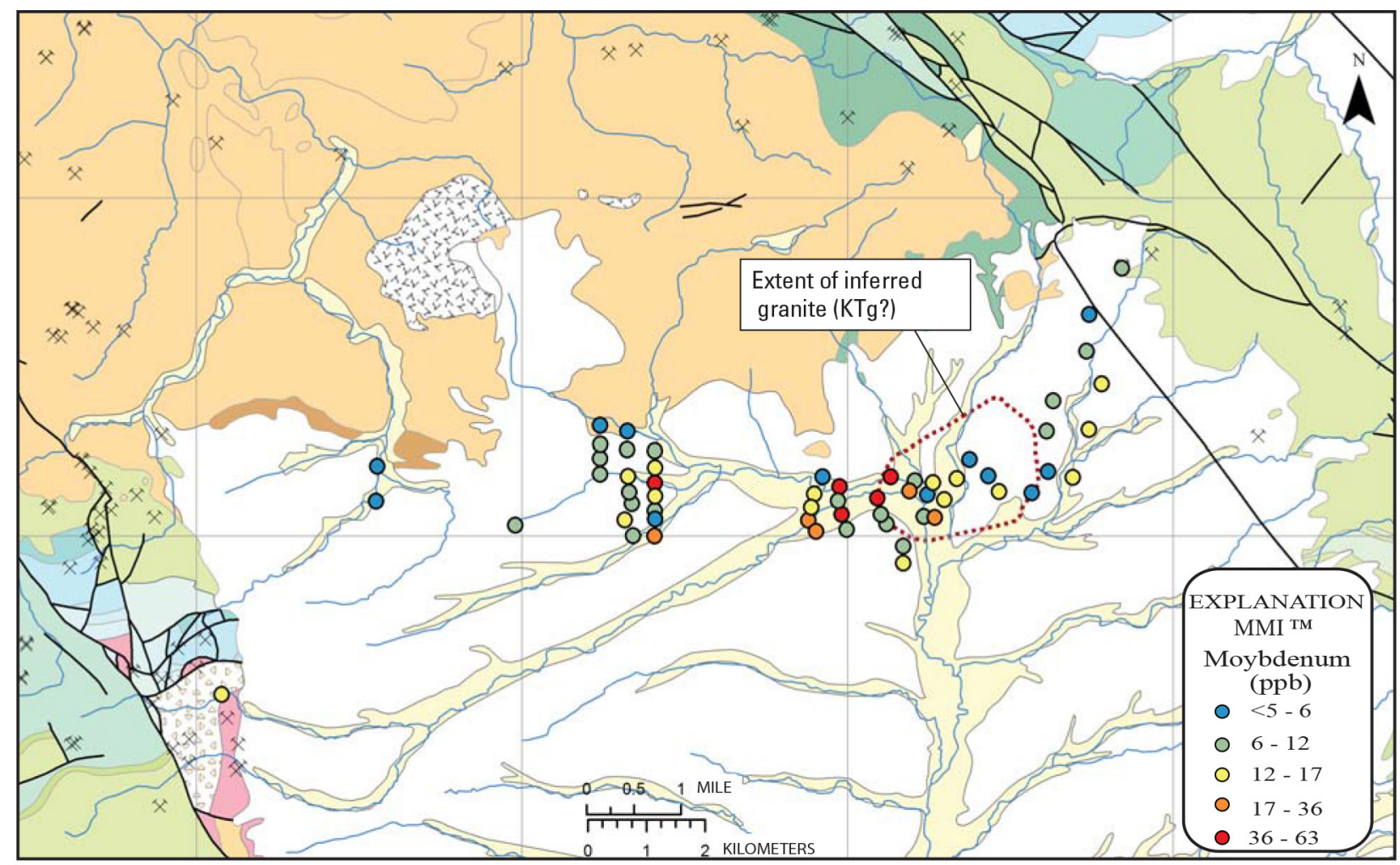

Figure A4. Geologic map of San Rafael Valley, Santa Cruz County, Arizona (described in figures 2 and 3), showing sample location and molybdenum concentrations in soil samples analyzed by Mobile Metal lon (MMI'M).

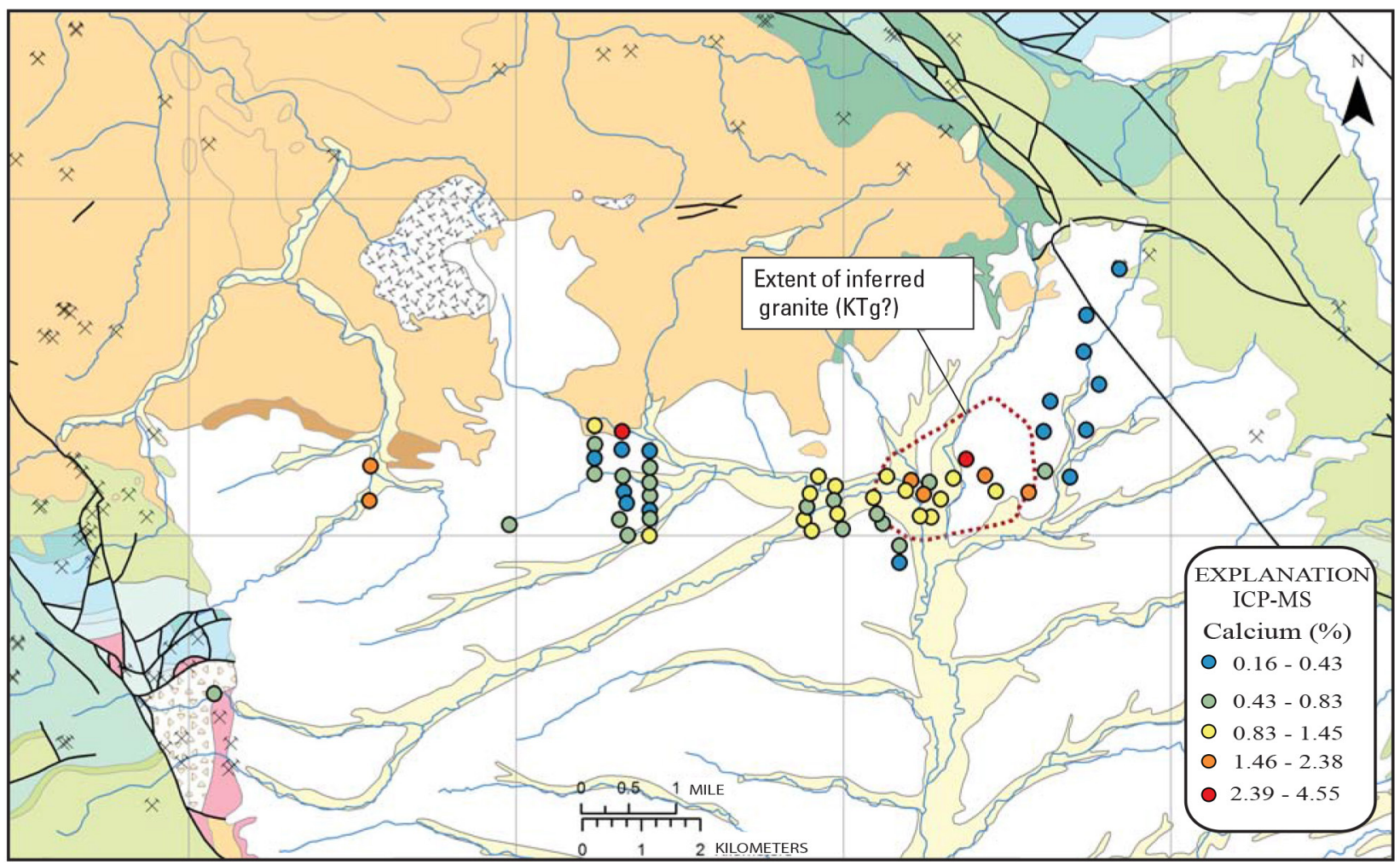

Figure A5. Geologic map of San Rafael Valley, Santa Cruz County, Arizona (described in figures 2 and 3), showing sample location and calcium concentrations in soil samples analyzed by inductively coupled plasma-mass spectrometry (ICP-MS). 


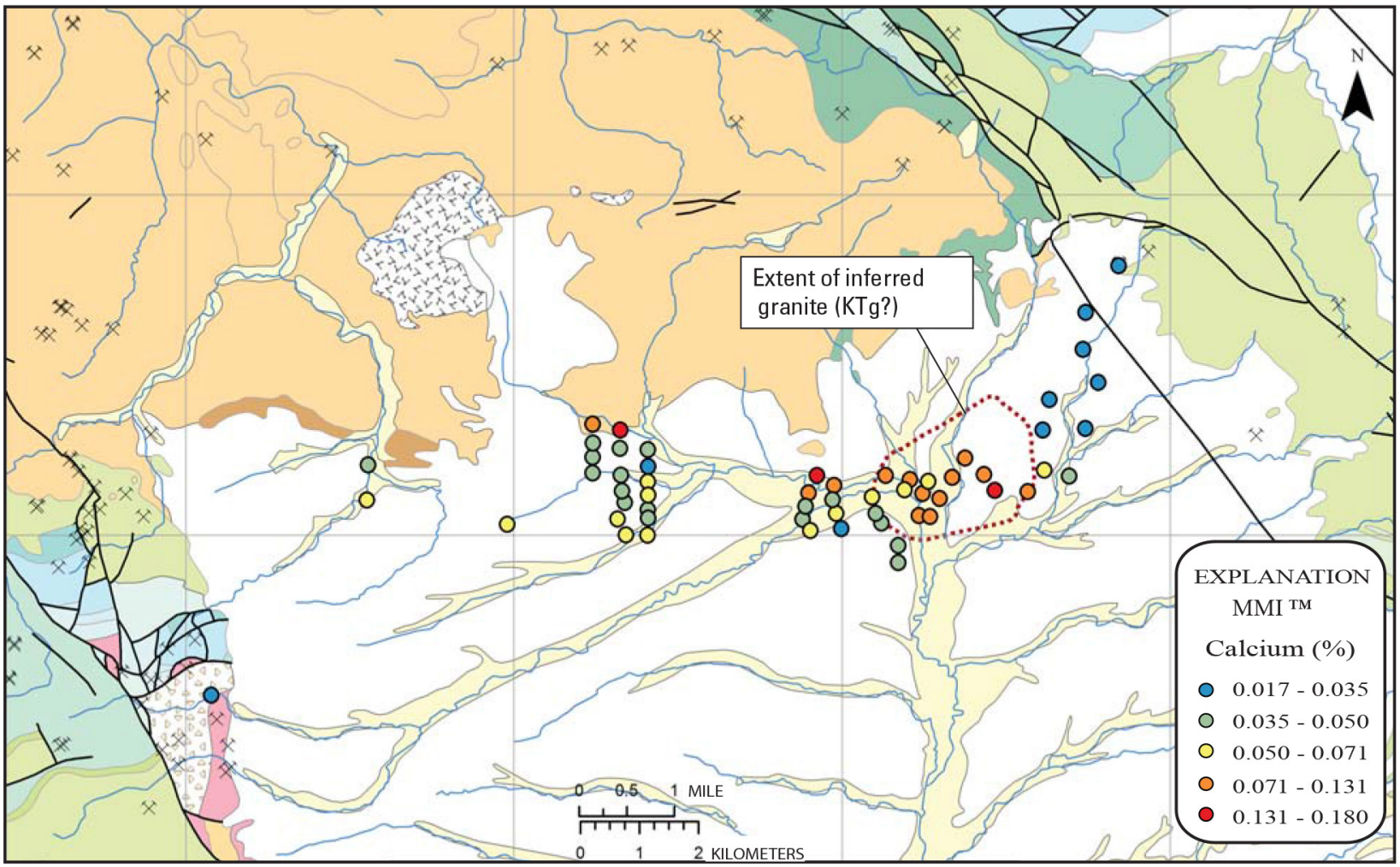

Figure A6. Geologic map of San Rafael Valley, Santa Cruz County, Arizona (described in figures 2 and 3), showing sample location and calcium concentrations in soil samples analyzed by Mobile Metal lon (MMI $\left.{ }^{\mathrm{TM}}\right)$.

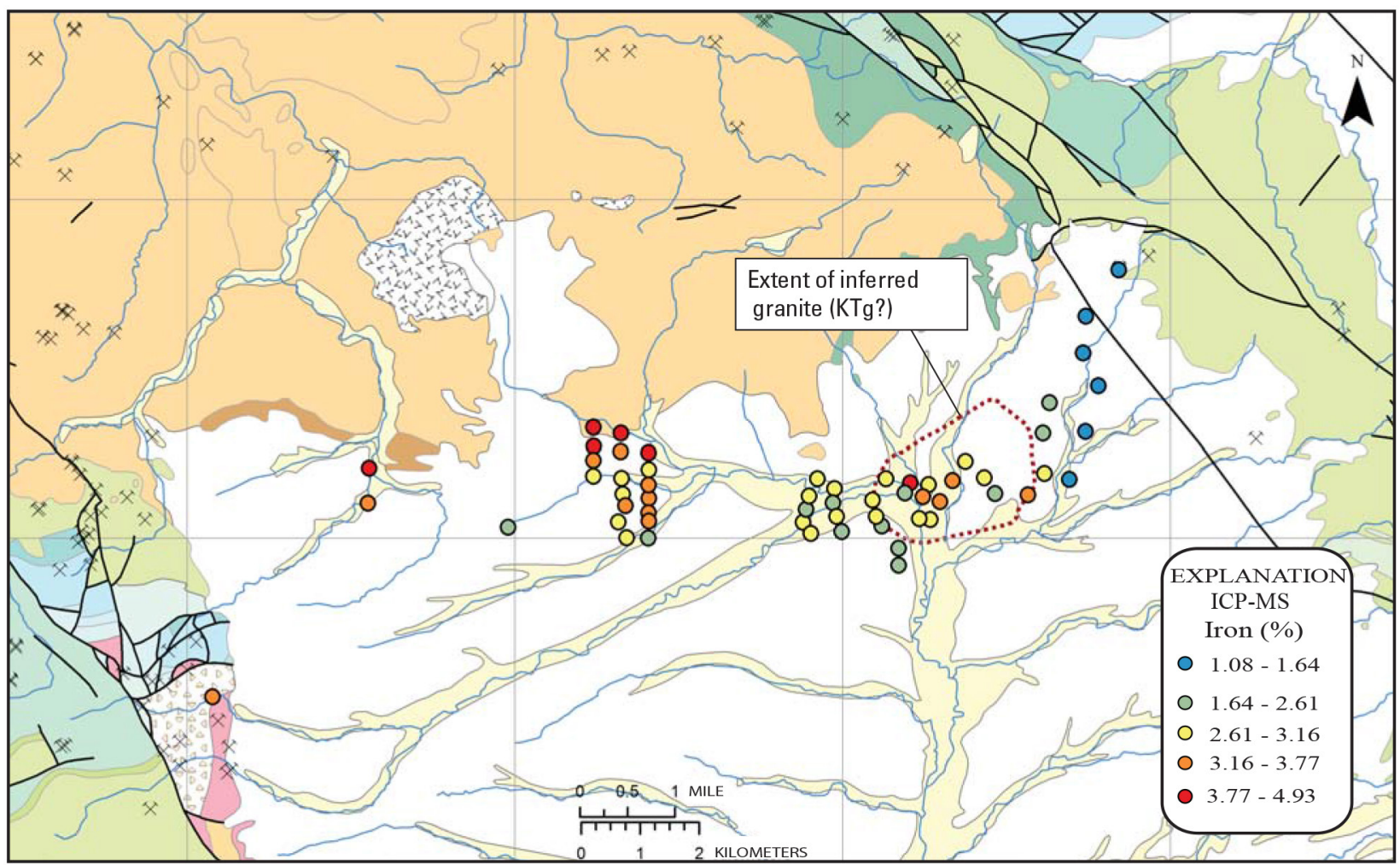

Figure A7. Geologic map of San Rafael Valley, Santa Cruz County, Arizona (described in figures 2 and 3), showing sample location and iron concentrations in soil samples analyzed by inductively coupled plasma-mass spectrometry (ICP-MS). 


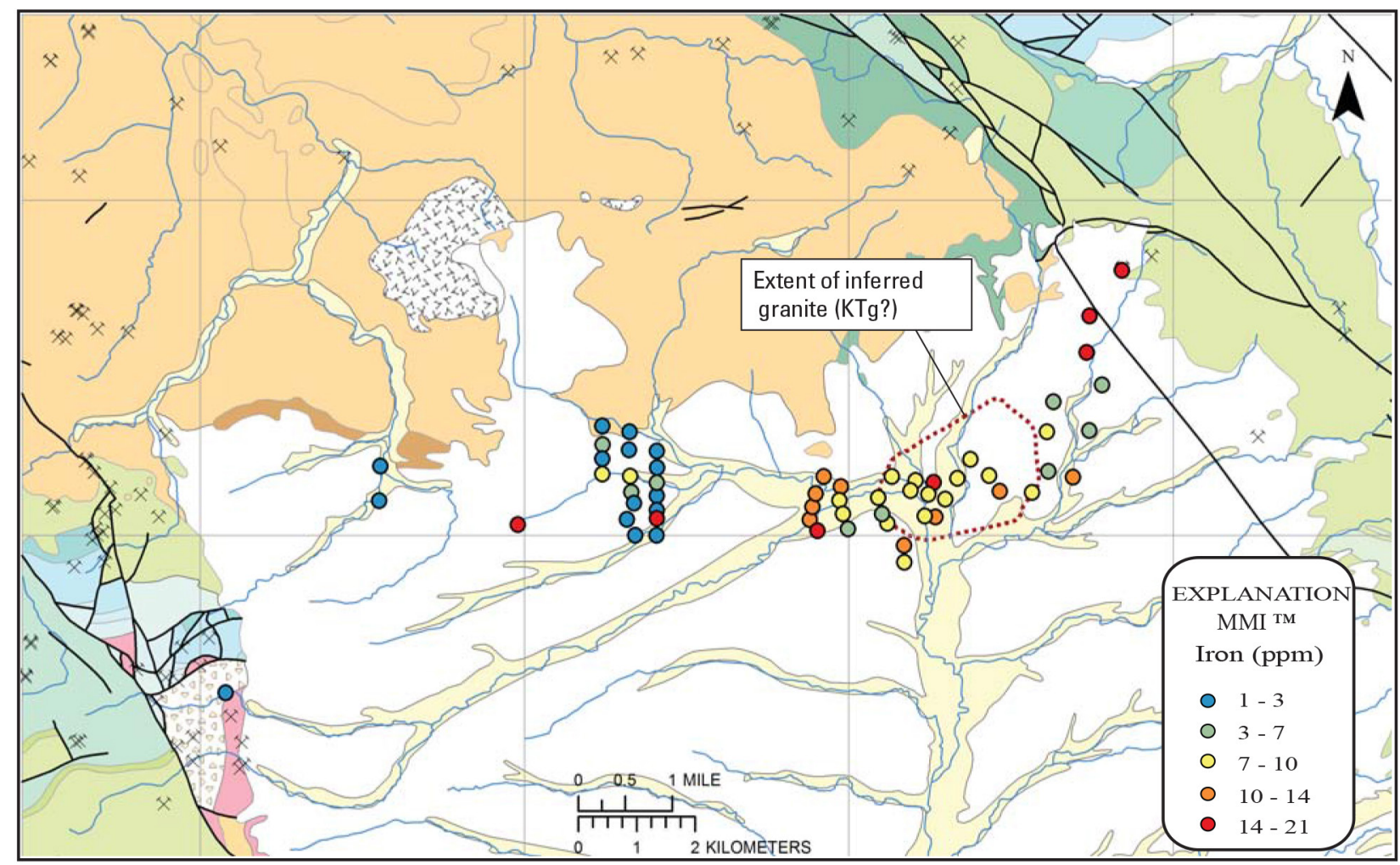

Figure A8. Geologic map of San Rafael Valley, Santa Cruz County, Arizona (described in figures 2 and 3), showing sample location and iron concentrations in soil samples analyzed by Mobile Metal Ion (MMI'T).

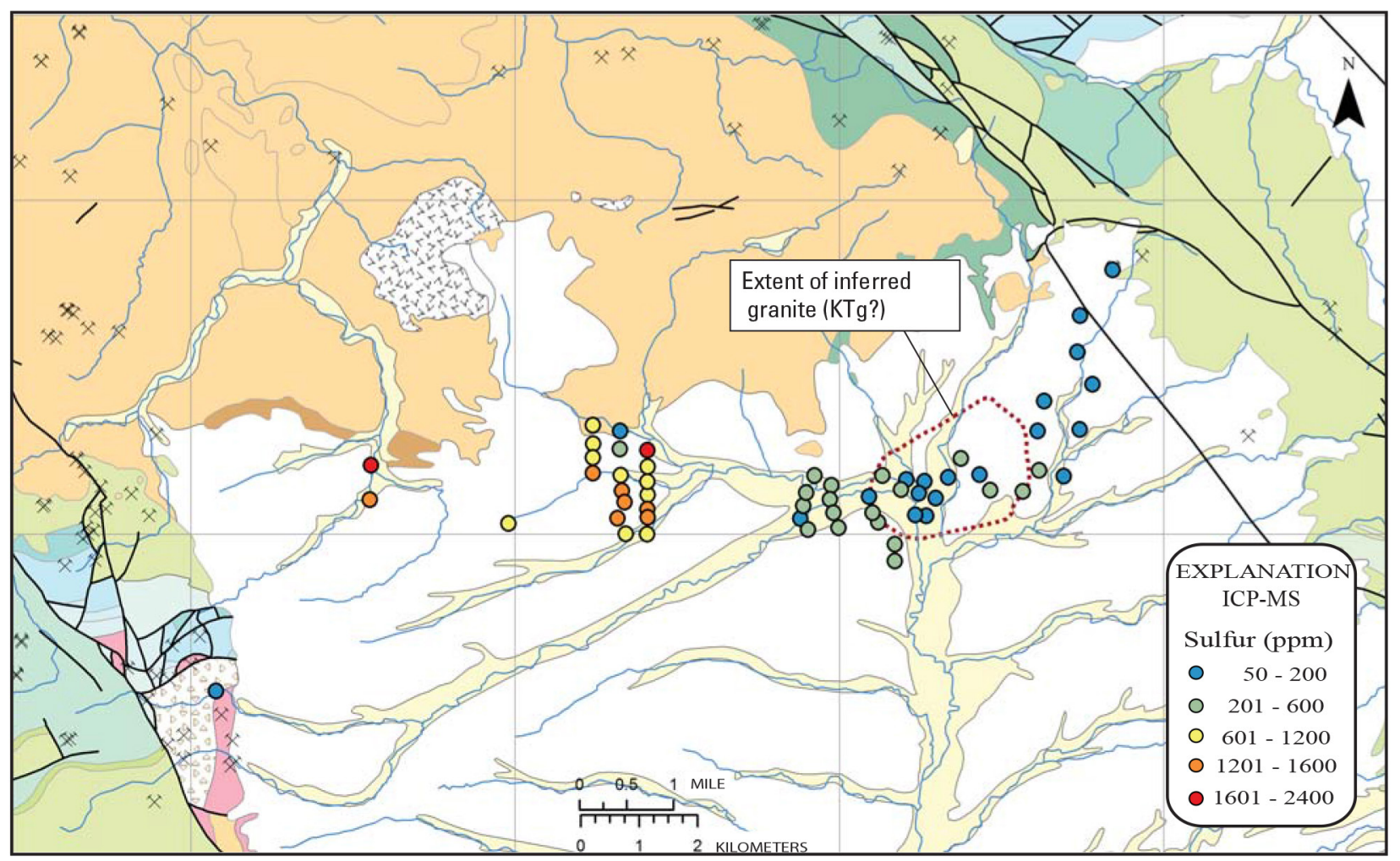

Figure A9. Geologic map of San Rafael Valley, Santa Cruz County, Arizona (described in figures 2 and 3), showing sample location and sulfur concentrations in soil samples analyzed by inductively coupled plasma-mass spectrometry (ICP-MS). 


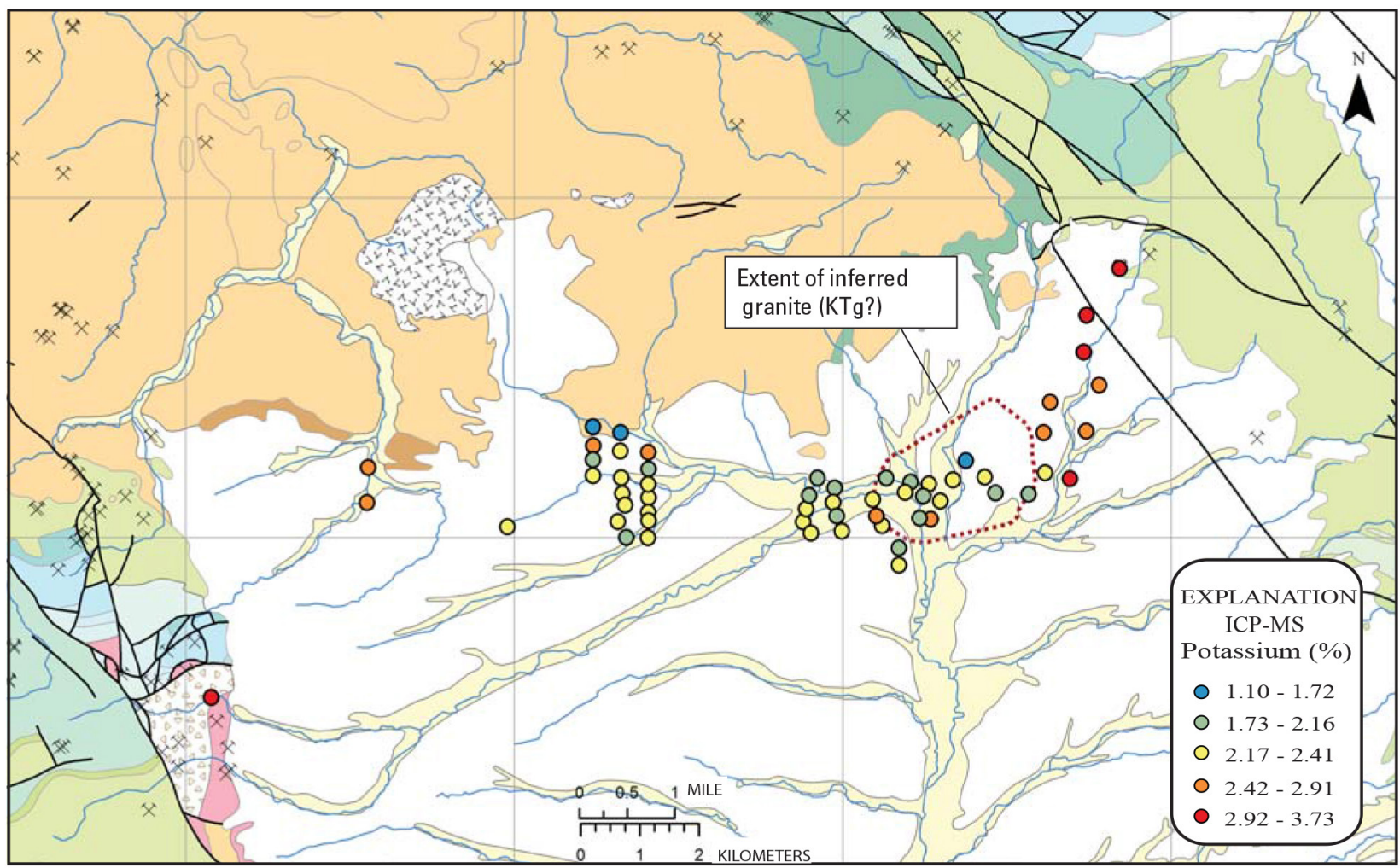

Figure A10. Geologic map of San Rafael Valley, Santa Cruz County, Arizona (described in figures 2 and 3), showing sample location and potassium concentrations in soil samples analyzed by inductively coupled plasma-mass spectrometry (ICP-MS).

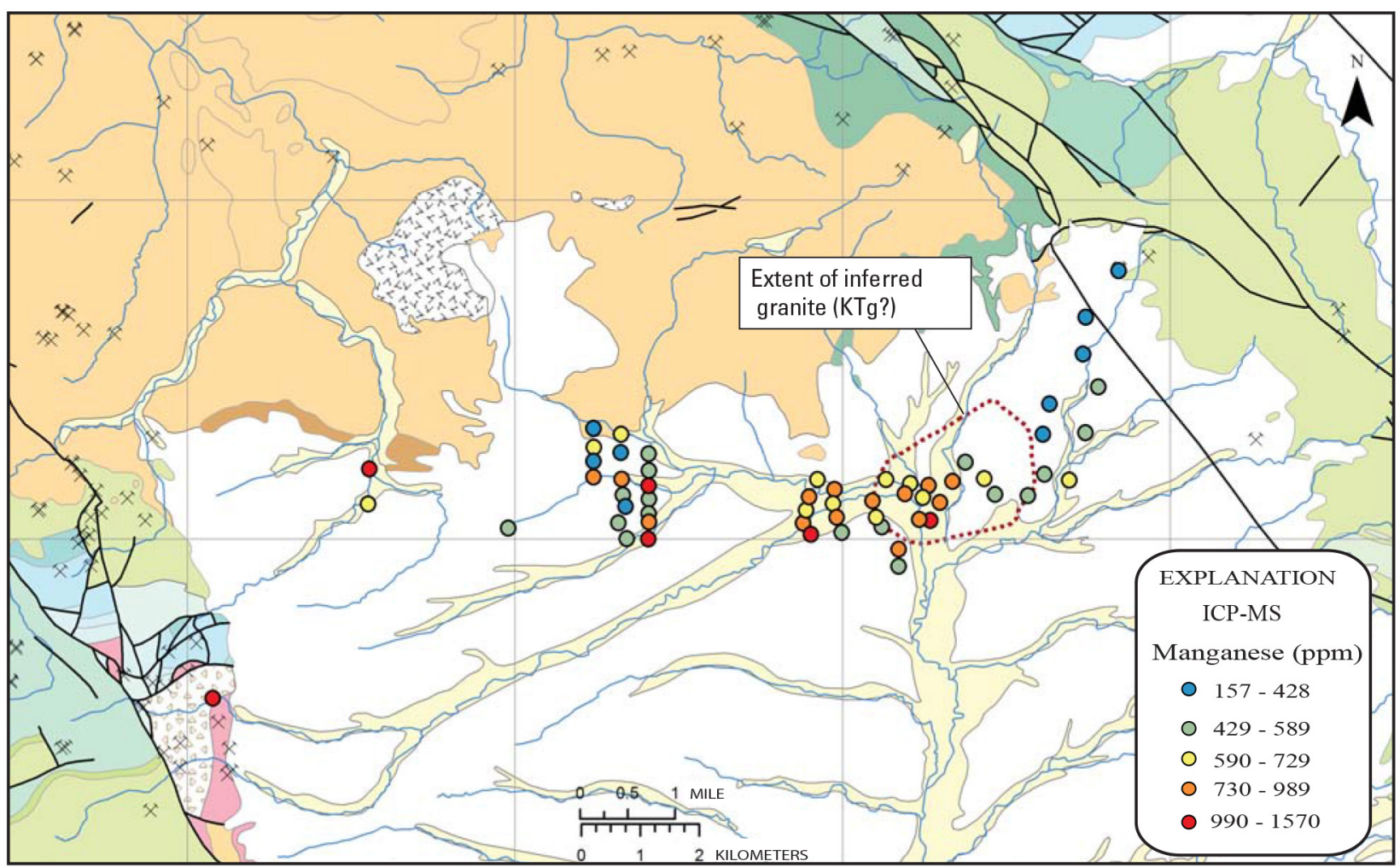

Figure A11. Geologic map of San Rafael Valley, Santa Cruz County, Arizona (described in figures 2 and 3), showing sample location and manganese concentrations in soil samples analyzed by inductively coupled plasma-mass spectrometry (ICP-MS). 


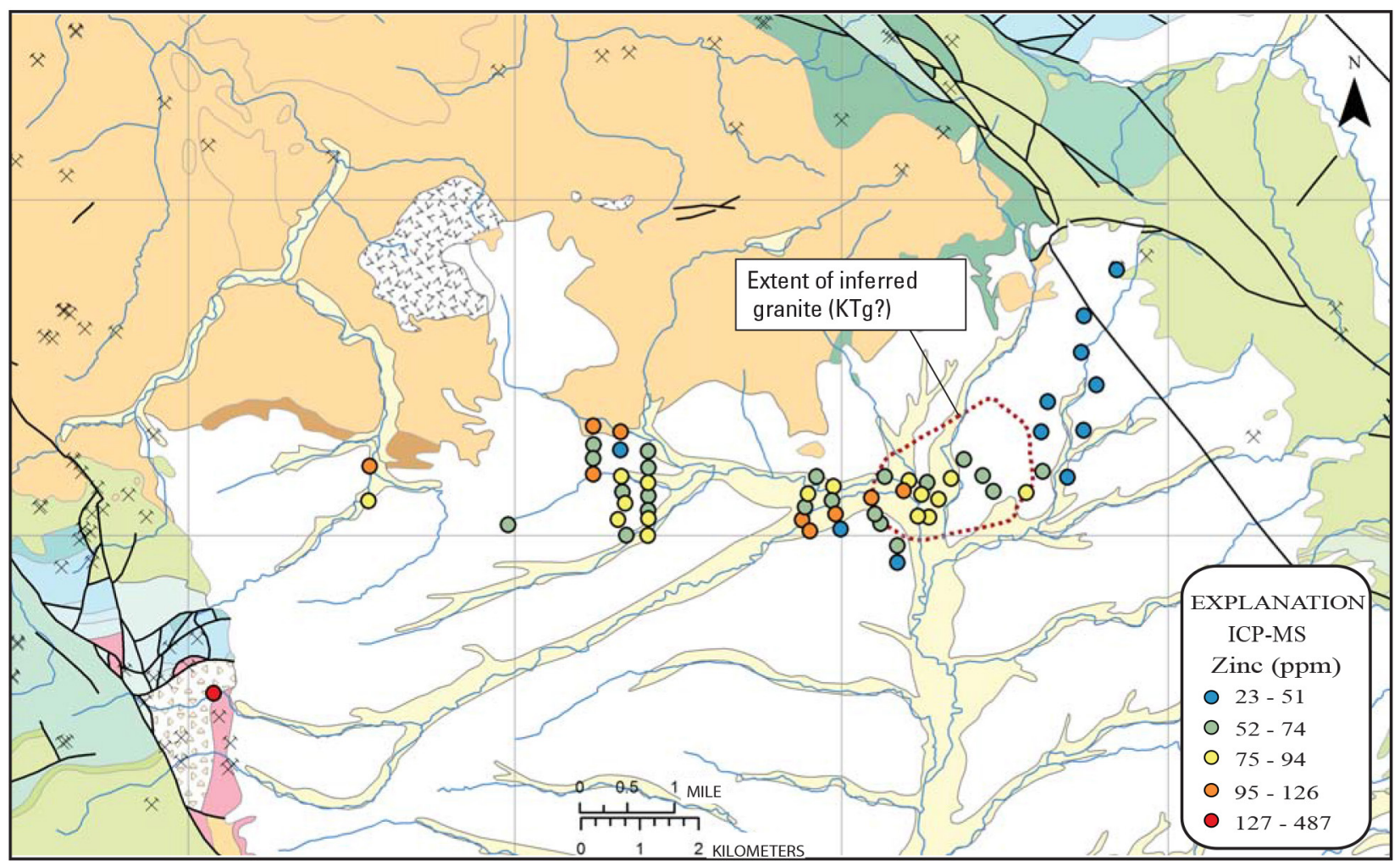

Figure A12. Geologic map of San Rafael Valley, Santa Cruz County, Arizona (described in figures 2 and 3), showing sample location and zinc concentrations in soil samples analyzed by inductively coupled plasma-mass spectrometry (ICP-MS). 


\section{Appendix B. Thematic maps showing distribution of factor scores determined} from inductively coupled plasma-mass spectrometry (ICP-MS) analyses of soil samples

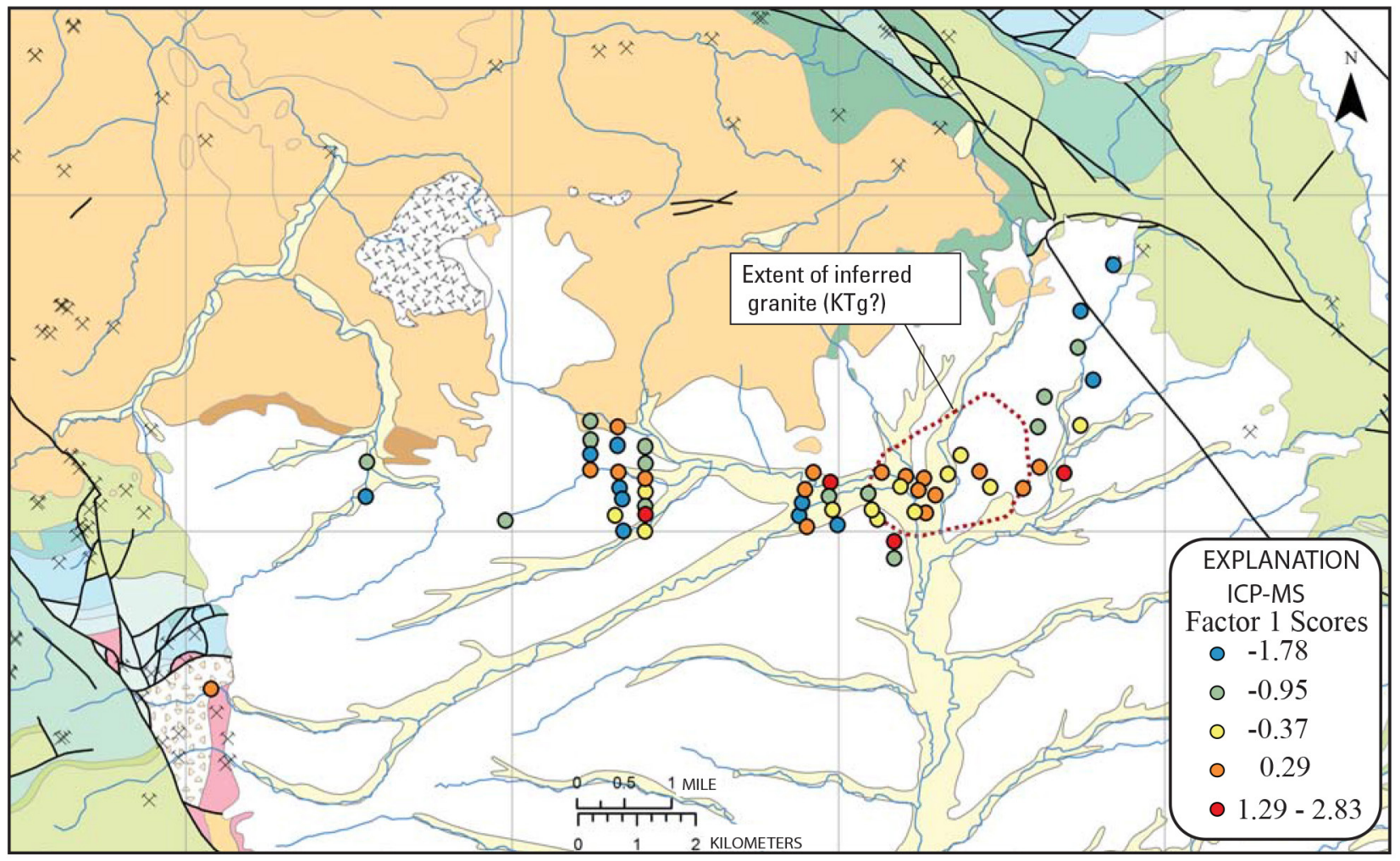

Figure B1. Geologic map of San Rafael Valley, Santa Cruz County, Arizona (described in figures 2 and 3), showing location of soil samples with factor scores displayed for factor 1 elements (Yb, Y, Tb, Lu, Be, Ce, Co, and La). 


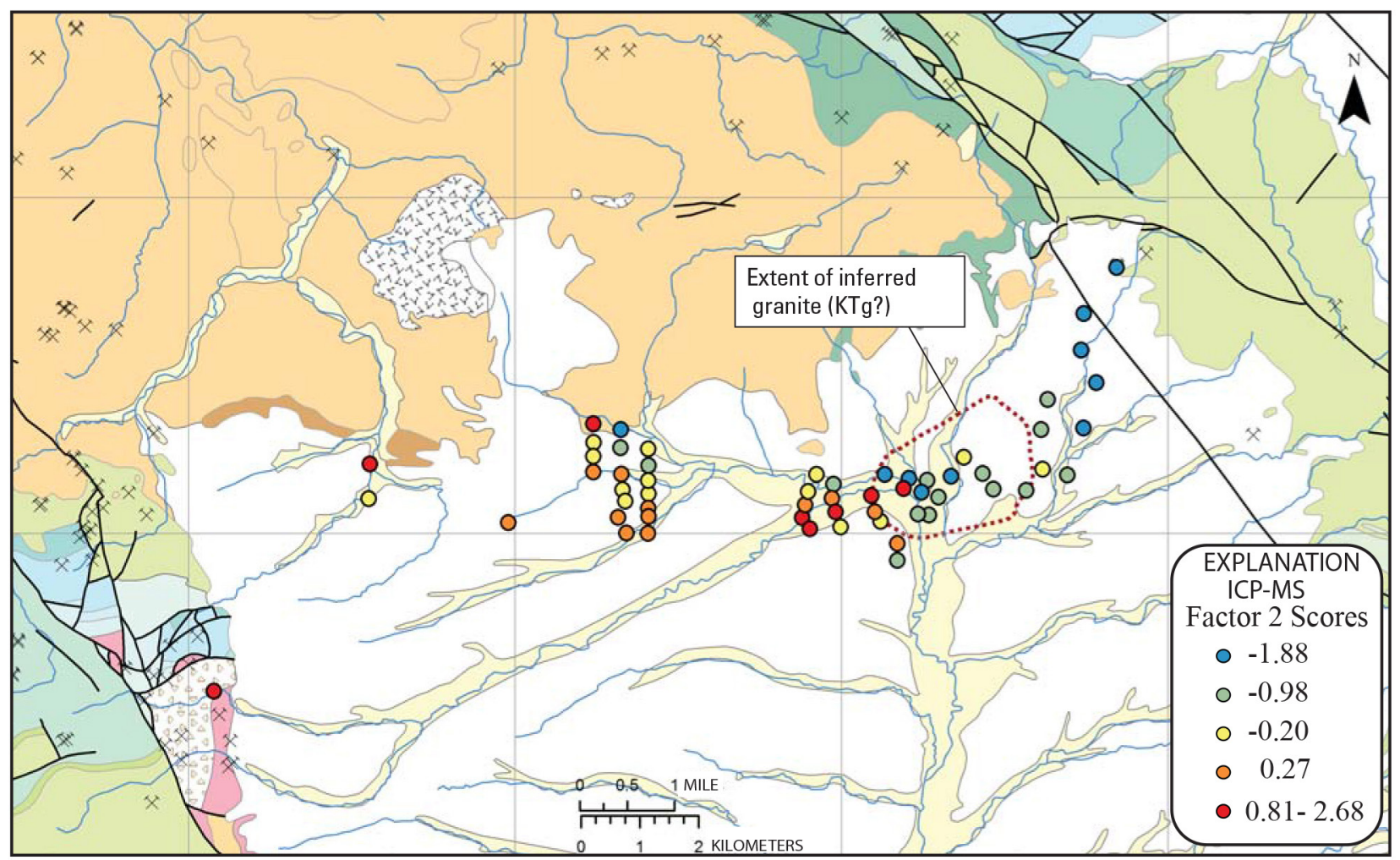

Figure B2. Geologic map of San Rafael Valley, Santa Cruz County, Arizona (described in figures 2 and 3), showing location of soil samples with factor scores displayed for factor 2 elements (In, Pb, Bi, Ag, Te, Zn, Cd, and Mo).

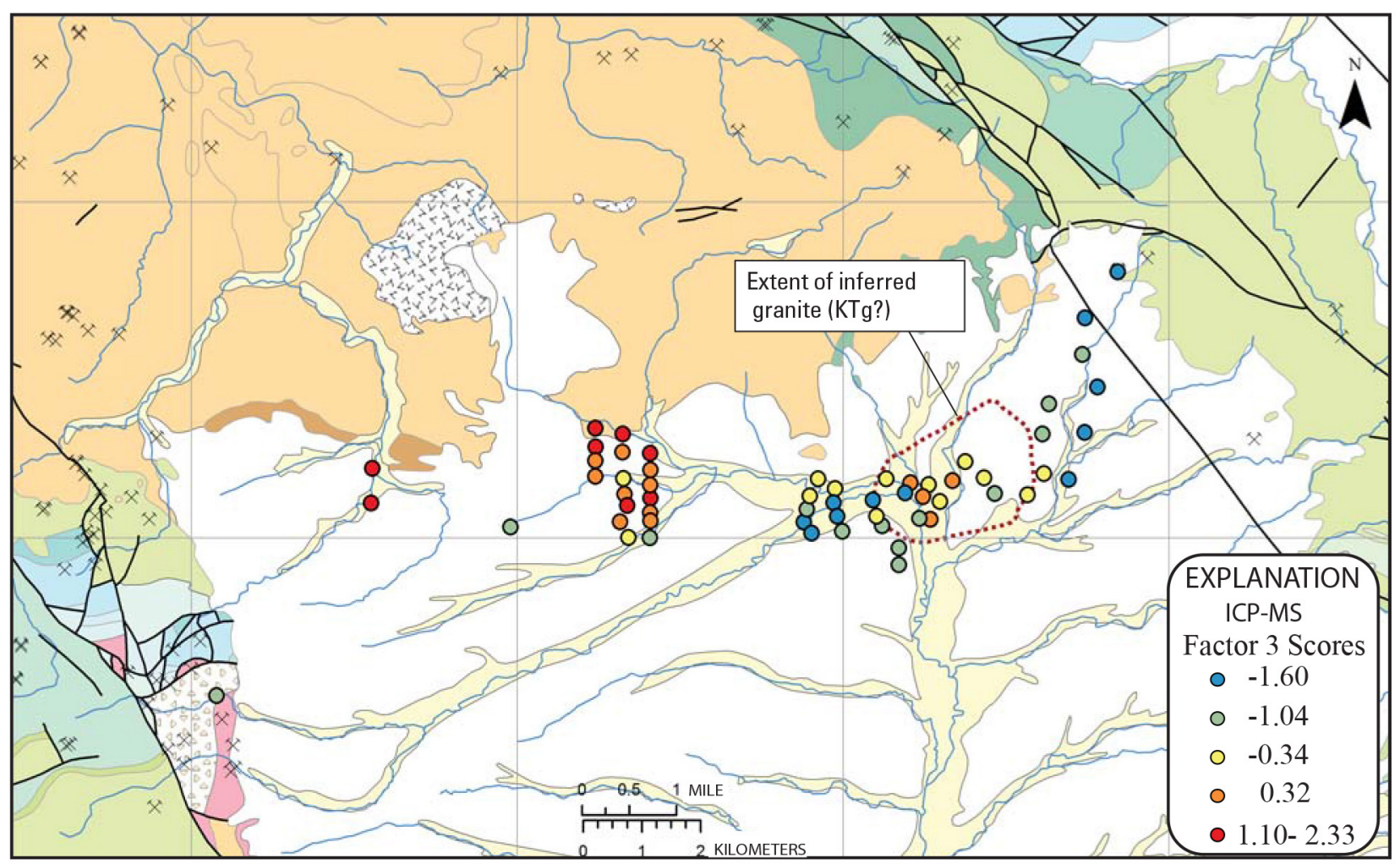

Figure B3. Geologic map of San Rafael Valley, Santa Cruz County, Arizona (described in figures 2 and 3), showing location of soil samples with factor scores displayed for factor 3 elements (Hf, Ti, Zr, Cu, Ni, Al, Fe, S, Sc, Li, P, and U). 


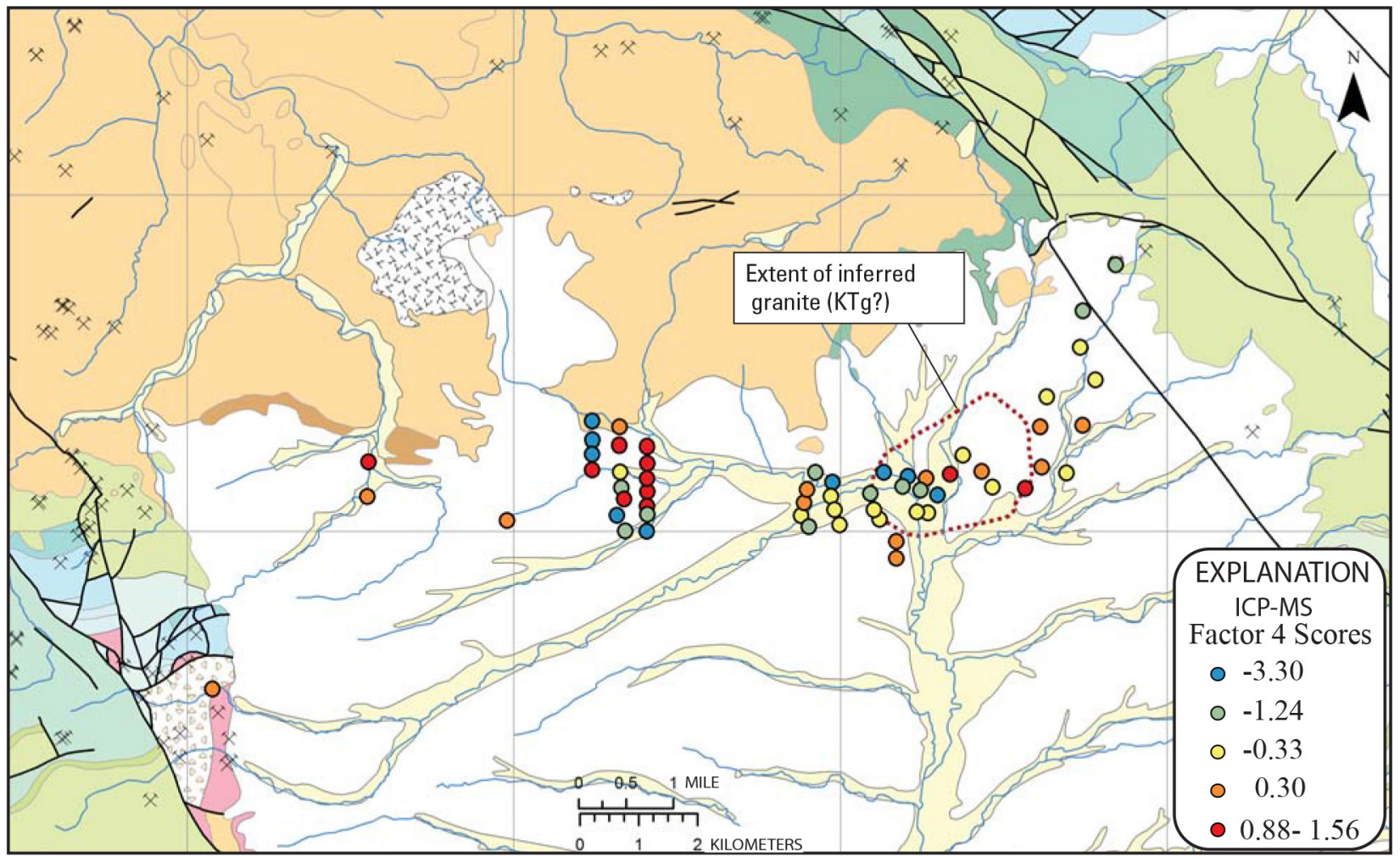

Figure B4. Geologic map of San Rafael Valley, Santa Cruz County, Arizona (described in figures 2 and 3), showing location of soil samples with factor scores displayed for factor 4 elements (Ta, Nb, W, Sb, and Sn).

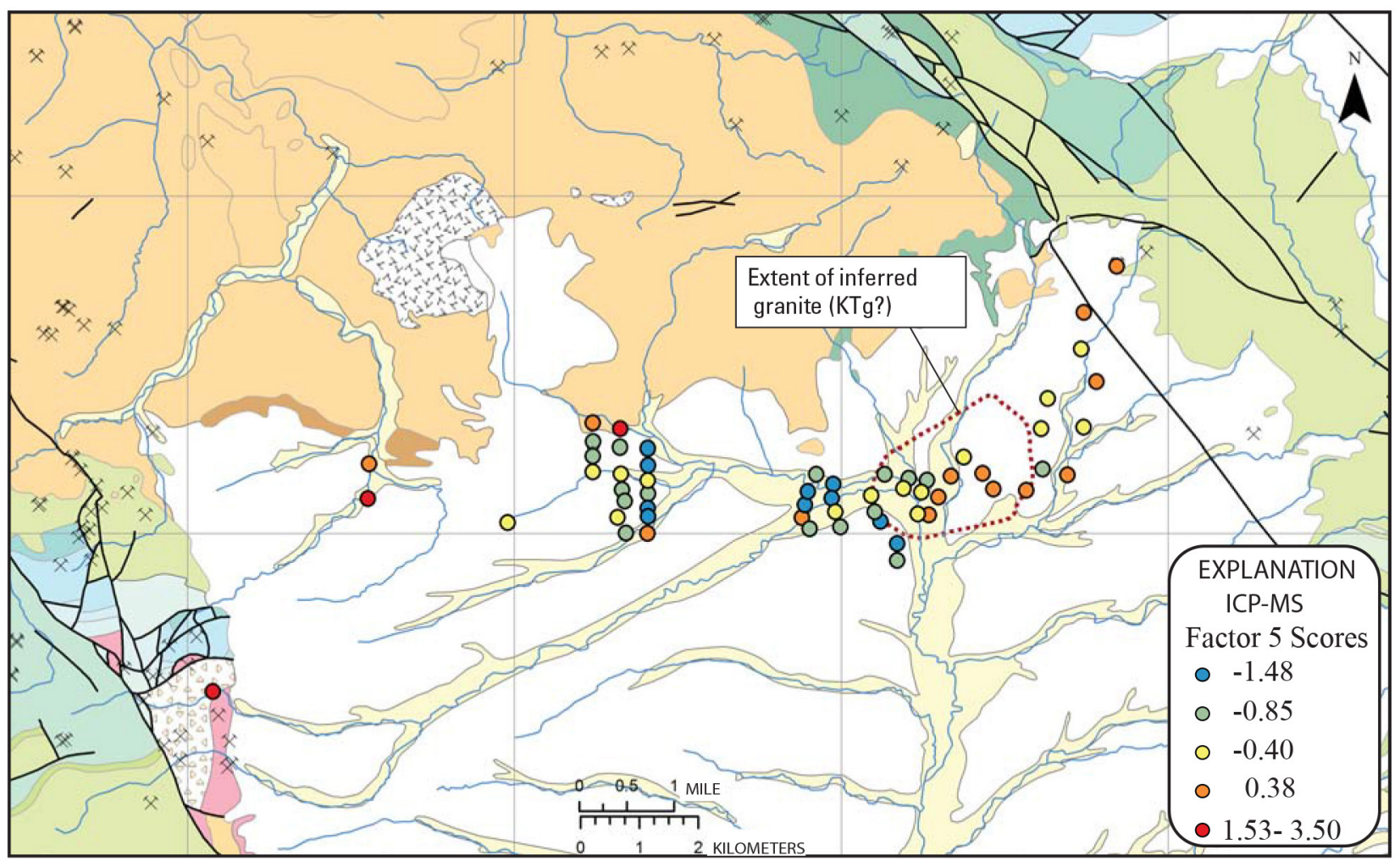

Figure B5. Geologic map of San Rafael Valley, Santa Cruz County, Arizona (described in figures 2 and 3), showing location of soil samples with factor scores displayed for factor 5 elements (As and -Th). 


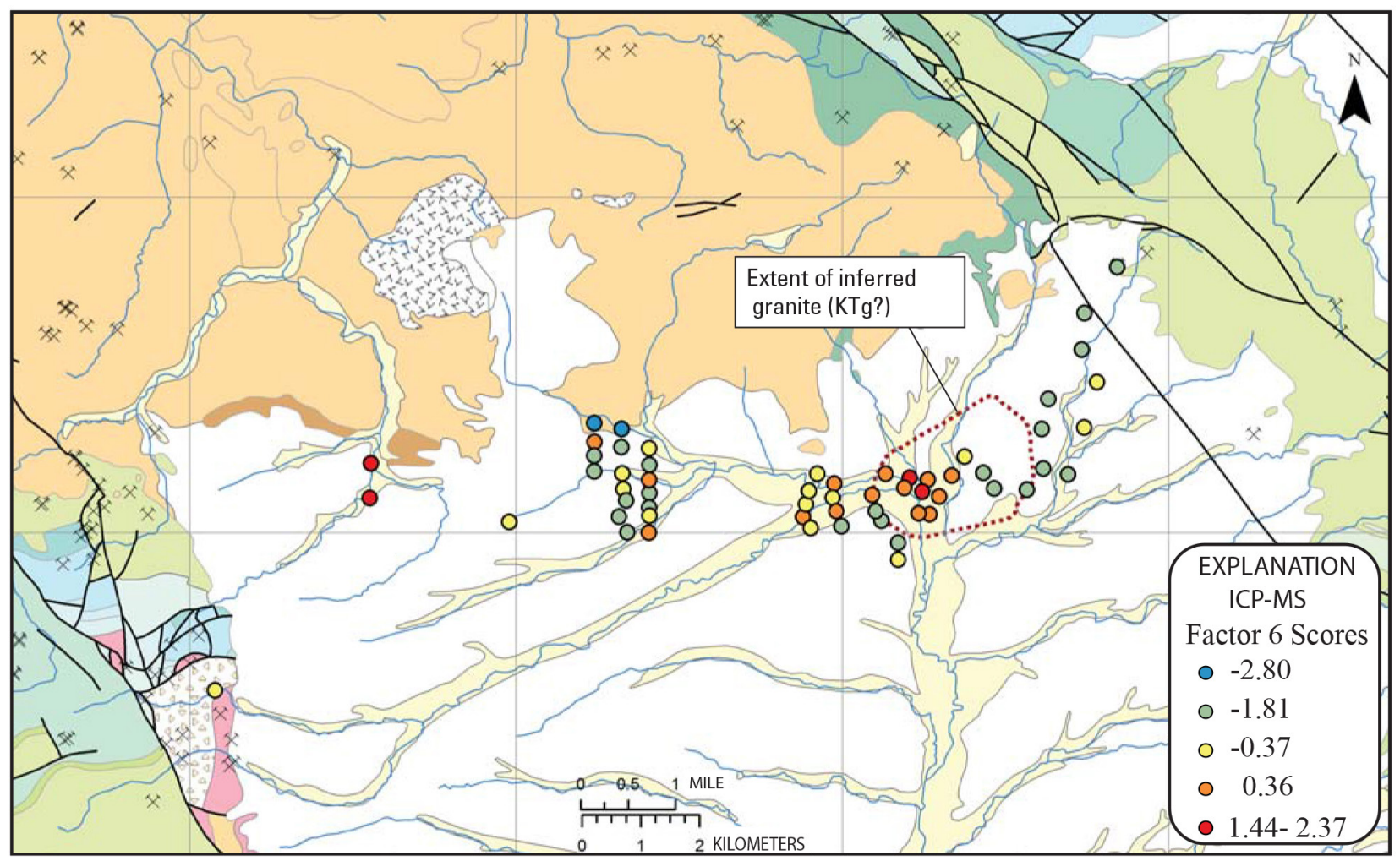

Figure B6. Geologic map of San Rafael Valley, Santa Cruz County, Arizona (described in figures 2 and 3), showing location of soil samples with factor scores displayed for factor 6 elements ( $\mathrm{Na}, \mathrm{Sr}, \mathrm{Ba}$, and $\mathrm{Mn}$ ).

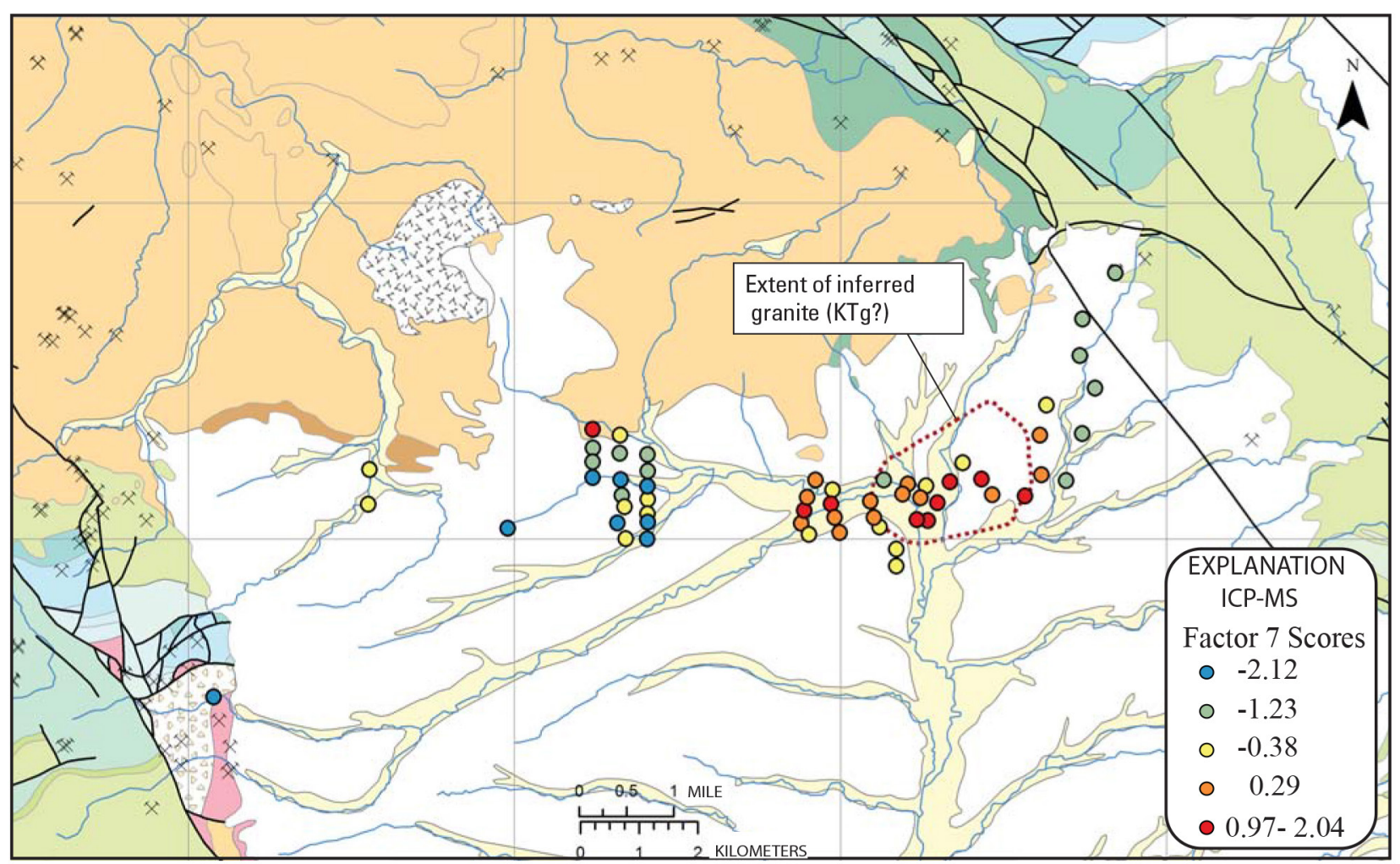

Figure B7. Geologic map of San Rafael Valley, Santa Cruz County, Arizona (described in figures 2 and 3), showing location of soil samples with factor scores displayed for factor 7 elements (Cs, Ga, Cr, Be, and V). 


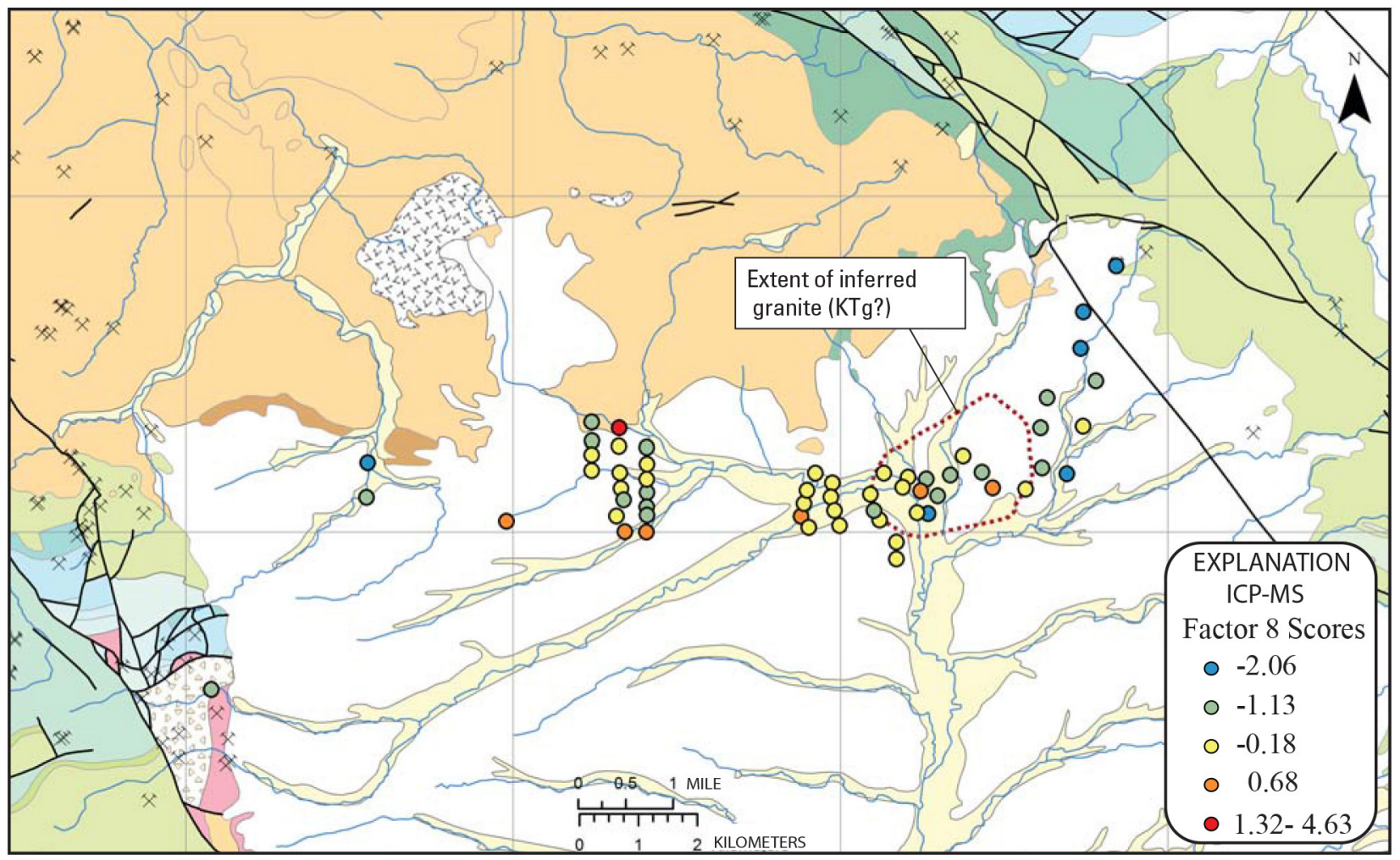

Figure B8. Geologic map of San Rafael Valley, Santa Cruz County, Arizona (described in figures 2 and 3), showing location of soil samples with factor scores displayed for factor 8 elements (K, Rb, $\mathrm{Tl}$, and $\mathrm{Sb})$. 


\section{Appendix C. Thematic maps showing distribution of factor scores determined from response ratios for Mobile Metal Ion ${ }^{\mathrm{TM}}$ (MMI) analyses of soil samples}

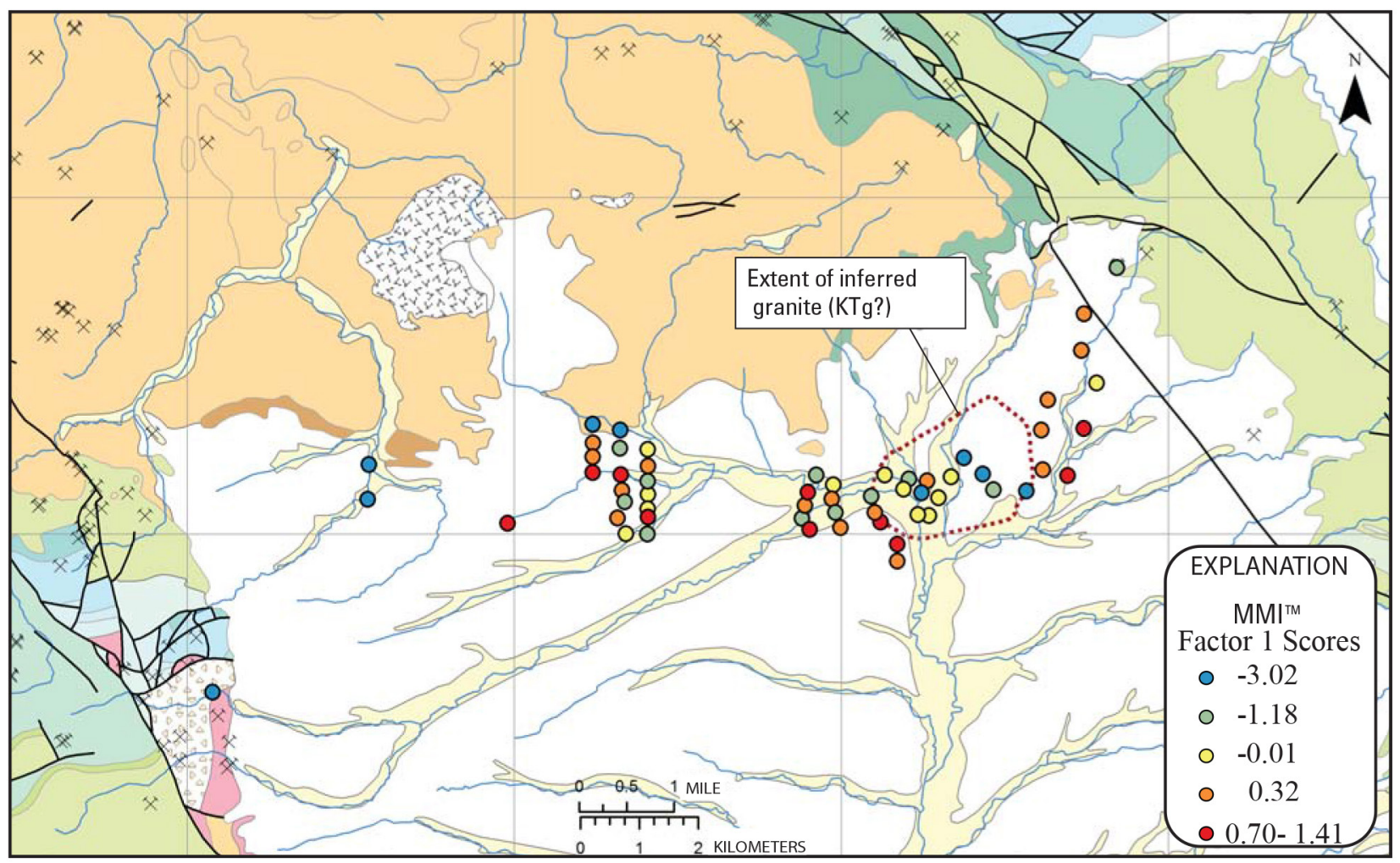

Figure C1. Geologic map of San Rafael Valley, Santa Cruz County, Arizona (described in figures 2 and 3), showing location of soil samples with factor scores displayed for factor 1 elements (Tb, Gd, Eu, Dy, Sm, Y, Er, Nd, Yb, Ce, Pr, La, Sc, Th, Zr, U, Al, and $\mathrm{Rb})$. 


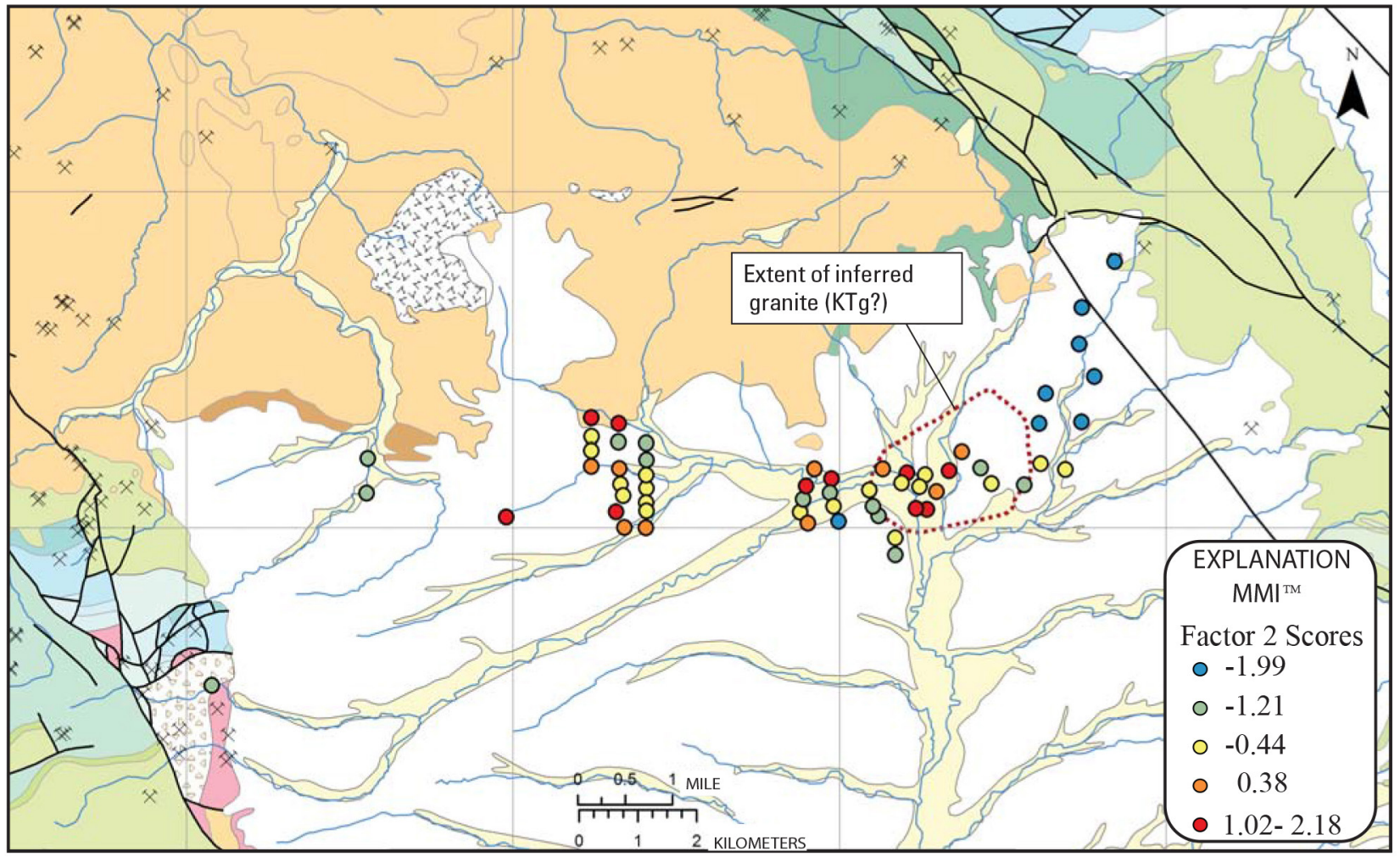

Figure C2. Geologic map of San Rafael Valley, Santa Cruz County, Arizona (described in figures 2 and 3), showing location of soil samples with factor scores displayed for factor 2 elements ( $\mathrm{Mg}, \mathrm{Sr}, \mathrm{Ni}, \mathrm{Ca}, \mathrm{Li}$, and $\mathrm{Cu}$ ).

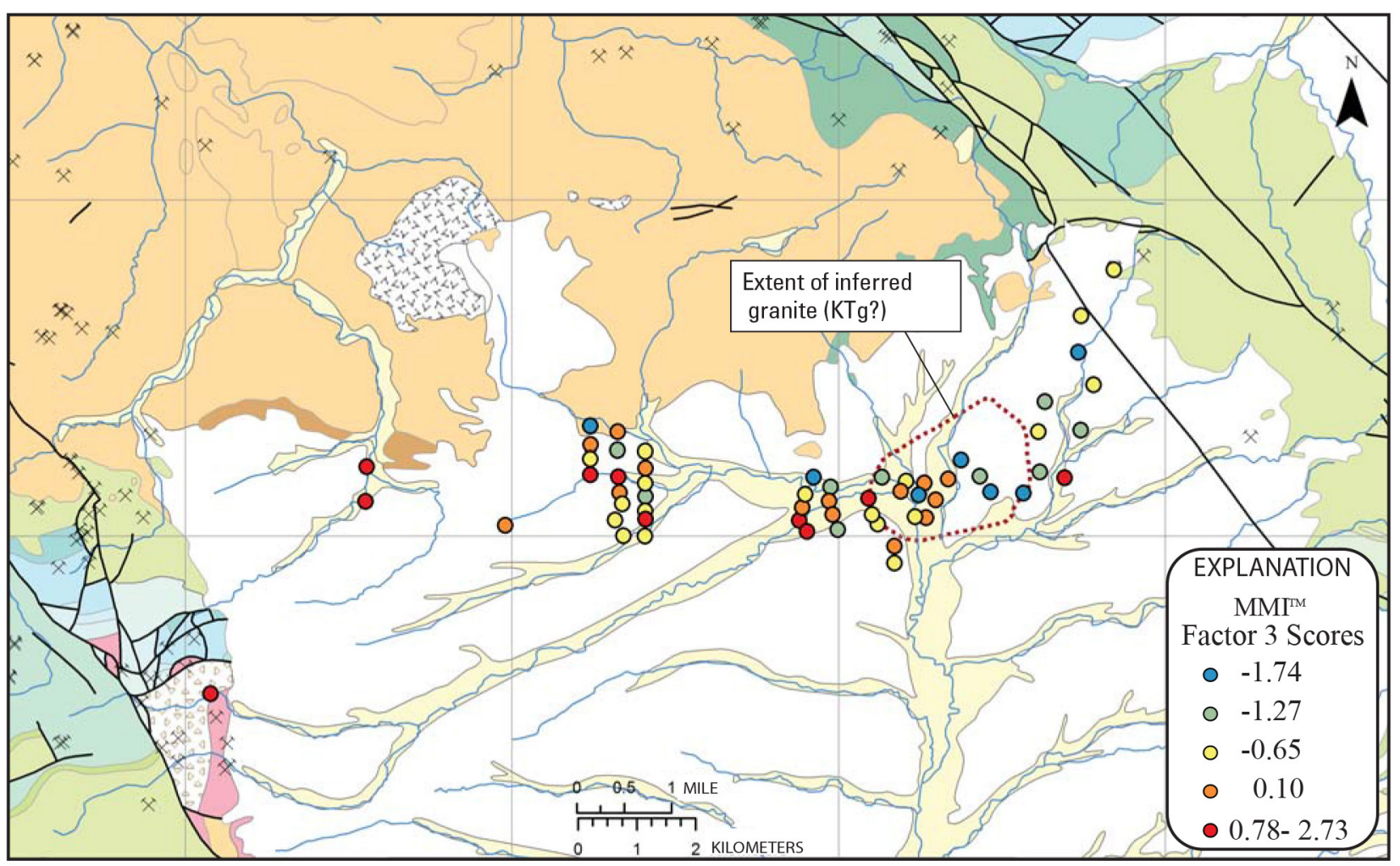

Figure C3. Geologic map of San Rafael Valley, Santa Cruz County, Arizona (described in figures 2 and 3), showing location of soil samples with factor scores displayed for factor 3 elements (Zn, Cd, -Ba, and -Co). 


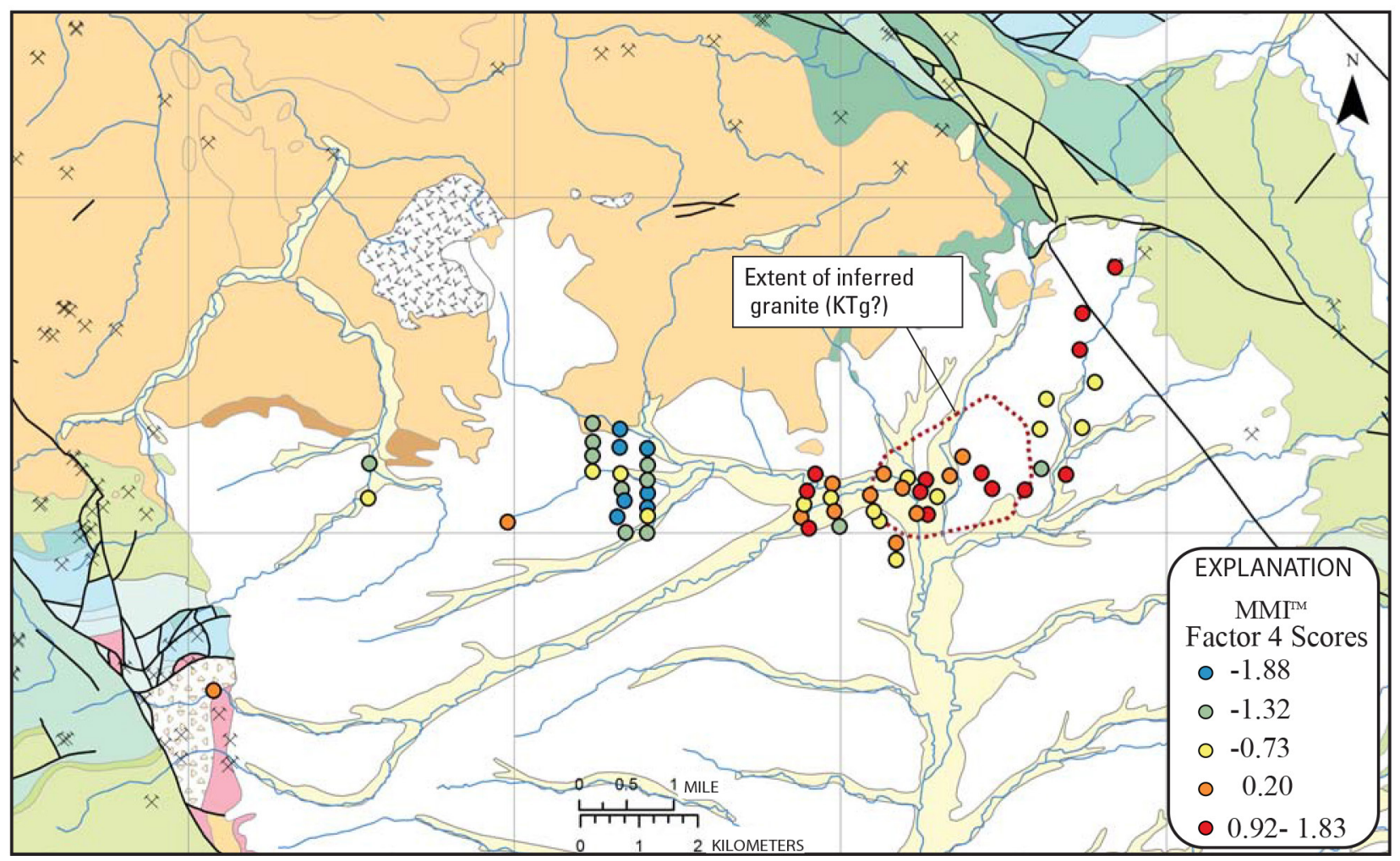

Figure C4. Geologic map of San Rafael Valley, Santa Cruz County, Arizona (described in figures 2 and 3), showing location of soil samples with factor scores displayed for factor 4 elements ( $\mathrm{Sb}, \mathrm{Fe}$, and W).

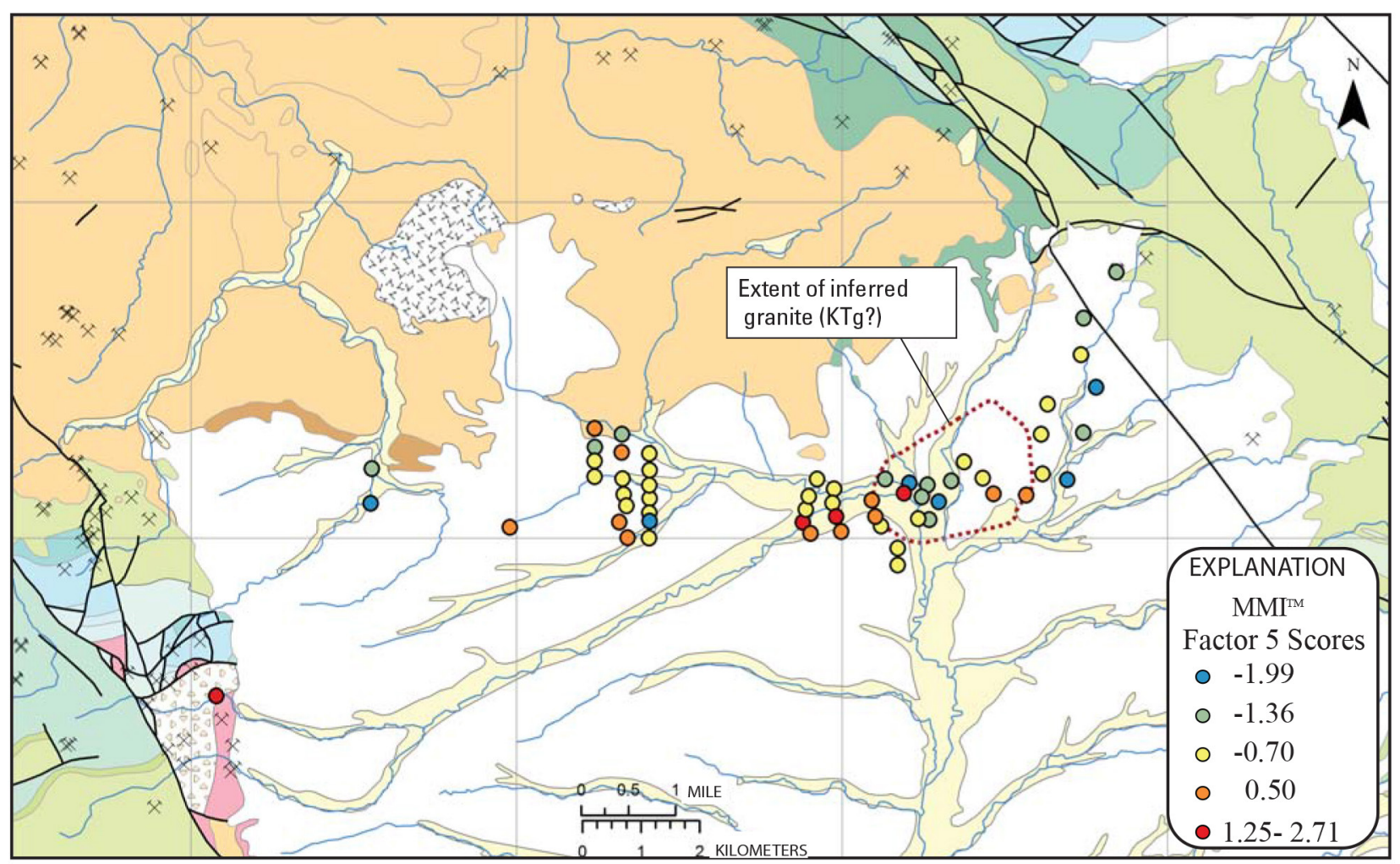

Figure C5. Geologic map of San Rafael Valley, Santa Cruz County, Arizona (described in figures 2 and 3), showing location of soil samples with factor scores displayed for factor 5 elements ( $\mathrm{Ag}, \mathrm{Au}$, and $\mathrm{Pb})$. 


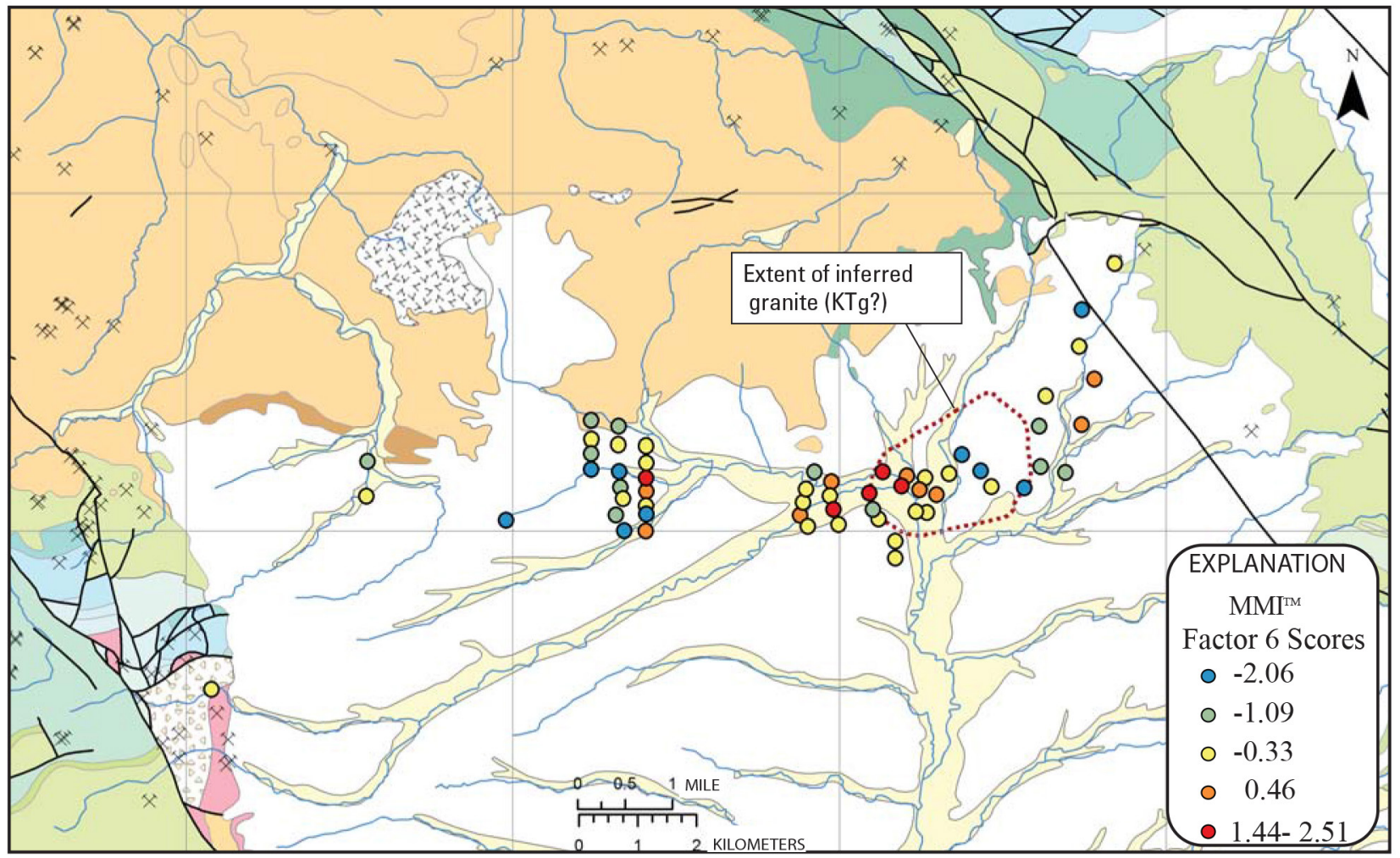

Figure C6. Geologic map of San Rafael Valley, Santa Cruz County, Arizona (described in figures 2 and 3), showing location of soil samples with factor scores displayed for the factor 6 element (Mo).

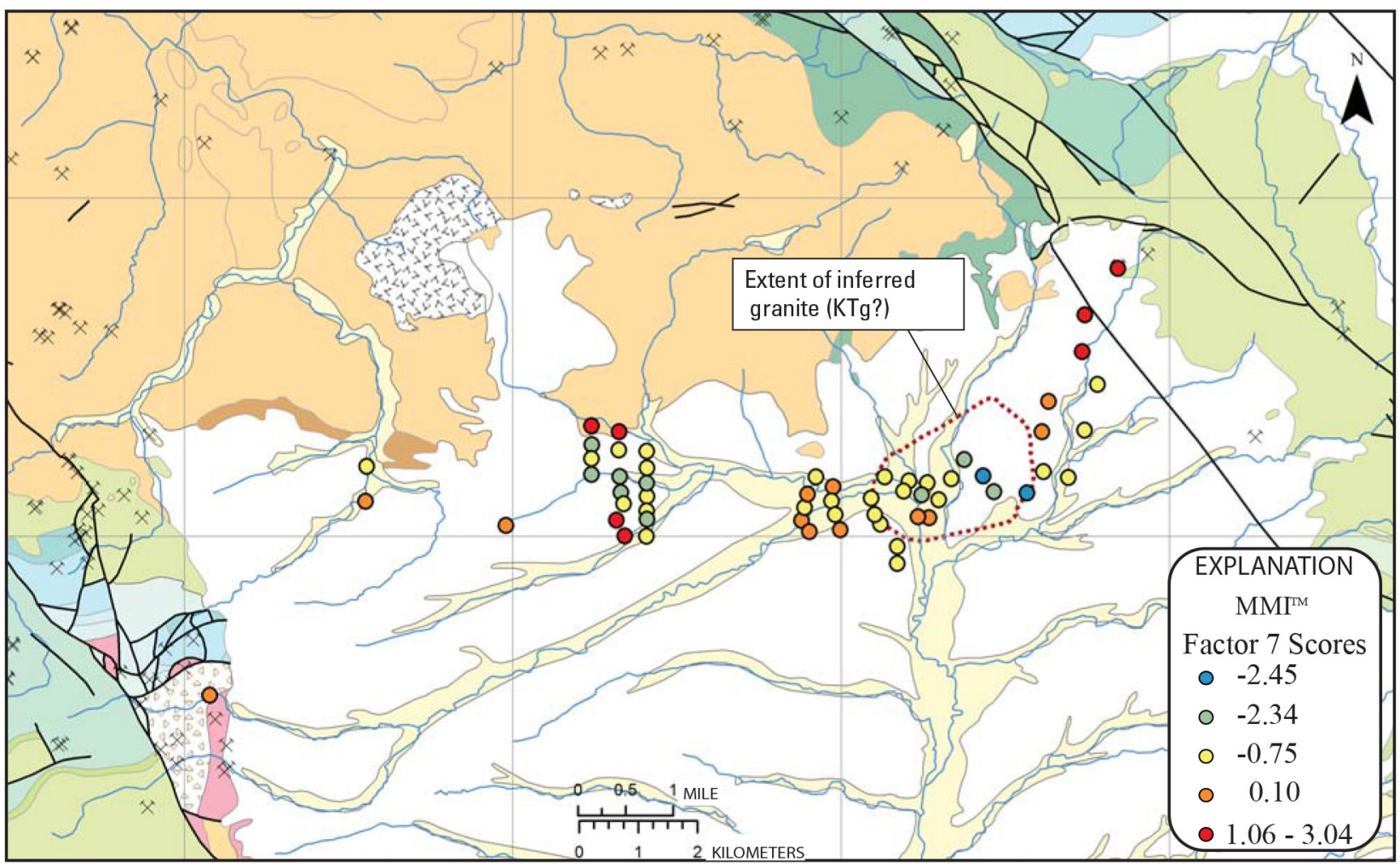

Figure C7. Geologic map of San Rafael Valley, Santa Cruz County, Arizona (described in figures 2 and 3), showing location of soil samples with factor scores displayed for the factor 7 element (Ti). 


\section{Appendix D. Thematic maps and biplots showing cluster results from inductively coupled plasma-mass spectrometry (ICP-MS) and Mobile Metal $\operatorname{Ion}^{\mathrm{TM}}$ (MMI) analyses of soil samples}
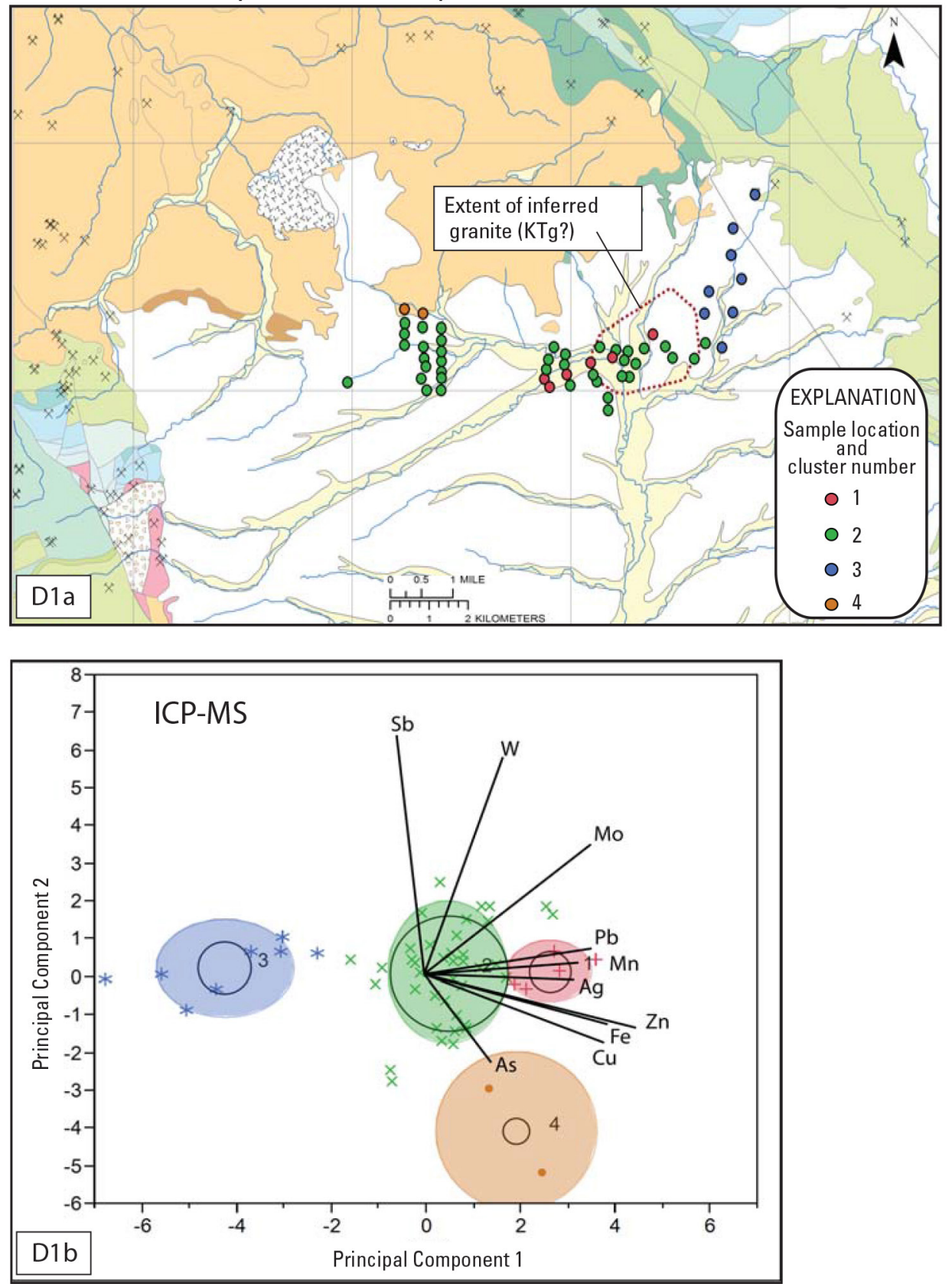

Figure D1a and D1b. Cluster groupings based on inductively coupled plasma-mass spectrometry (ICP-MS) analyses of soil samples plotted in figure D1a on a geologic map of the San Rafael Valley, Santa Cruz County, Arizona (described in figures 2 and 3), and biplot with biplot rays showing the four distinct clusters in figure D1b. 

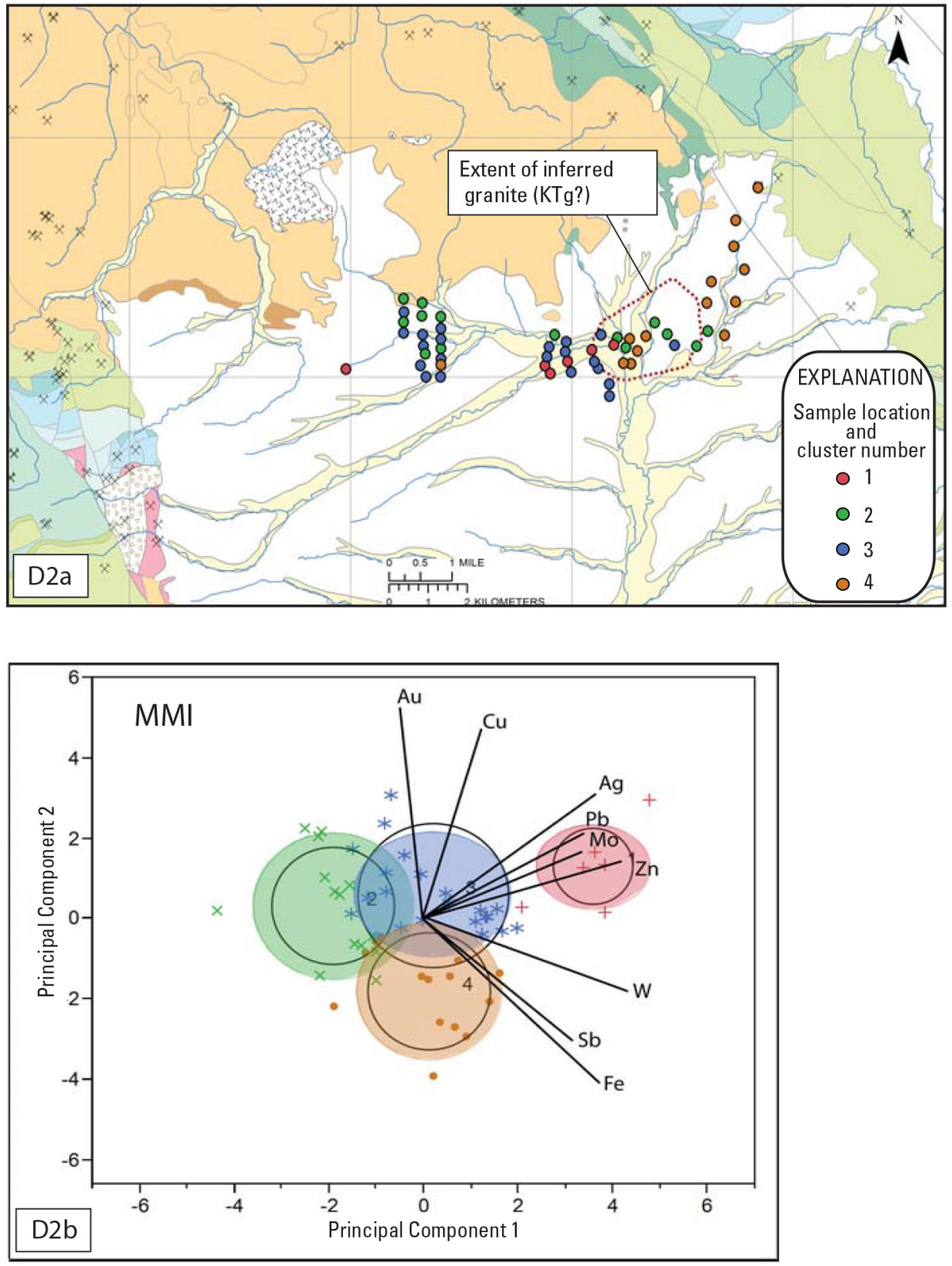

Figure D2a and D2b. Cluster groupings based on Mobile Metal Ion ${ }^{\mathrm{TM}}$ (MMI) analyses of soil samples plotted in figure D2a on a geologic map of the San Rafael Valley, Santa Cruz County, Arizona (described in figures 2 and 3), and biplot with biplot rays showing the four distinct clusters in figure D2b. 

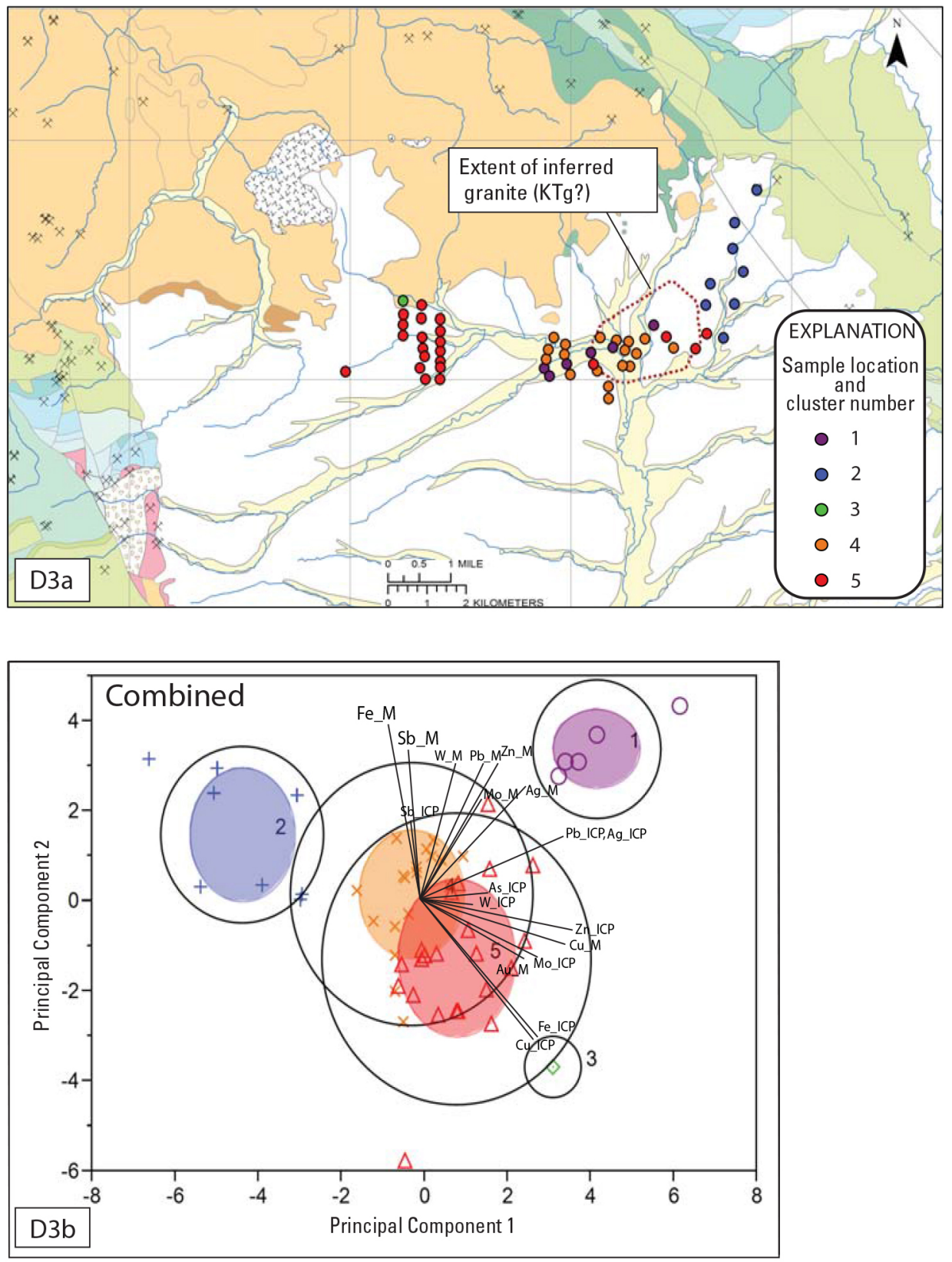

Figures D3a and D3b. Cluster groupings of the combined inductively coupled plasma-mass spectrometry and Mobile Metal Ion ${ }^{\mathrm{TM}}$ analyses of soil samples plotted in figure D3a on a geologic map of the San Rafael Valley, Santa Cruz County, Arizona (described in figures 2 and 3 ), and biplot with biplot rays showing the five distinct clusters in figure D3b. 
ISSN (online) 2331-1258

DOI URLhttp://dx.doi.org/10.3133/ofr20131149 